\title{
Discriminators of mouse bladder response to intravesical Bacillus Calmette-Guerin (BCG)
}

\author{
Marcia R Saban1, Cindy Simpson ${ }^{1}$, Carole Davis¹, Gemma Wallis², \\ Nicholas Knowlton ${ }^{2}$, Mark Barton Frank ${ }^{2}$, Michael Centola², \\ Randle M Gallucci ${ }^{3}$ and Ricardo Saban*1
}

Address: ${ }^{1}$ College of Medicine, Department of Physiology, Oklahoma University Health Sciences Center (OUHSC), Ohlahoma City, OK 73104 , USA, ${ }^{2}$ Oklahoma Medical Research Foundation (OMRF), Microarray Research Facility, Oklahoma City, OK, 73104, USA and ${ }^{3}$ Pharmaceutical Sciences, OUHSC, Oklahoma City, OK 73104, USA

Email: Marcia R Saban - marcia-saban@ouhsc.edu; Cindy Simpson - cindy-simpson@ouhsc.edu; Carole Davis - carole-davis@ouhsc.edu; Gemma Wallis - Gemma-Wallis@mail.omrf.ouhsc.edu; Nicholas Knowlton - Nicholas-Knowlton@omrf.ouhsc.edu; Mark Barton Frank - BartFrank@omrf.ouhsc.edu; Michael Centola - mike-centola@omrf.ouhsc.edu; Randle M Gallucci - Randy-Gallucci@ouhsc.edu; Ricardo Saban* - ricardo-saban@ouhsc.edu

* Corresponding author

Published: 16 May 2007

BMC Immunology 2007, 8:6 doi:10.1 I86/147|-2172-8-6
Received: 24 February 2007

Accepted: 16 May 2007

This article is available from: http://www.biomedcentral.com/147I-2/72/8/6

(C) 2007 Saban et al; licensee BioMed Central Ltd.

This is an Open Access article distributed under the terms of the Creative Commons Attribution License (http://creativecommons.org/licenses/by/2.0), which permits unrestricted use, distribution, and reproduction in any medium, provided the original work is properly cited.

\begin{abstract}
Background: Intravesical Bacillus Calmette-Guerin (BCG) is an effective treatment for bladder superficial carcinoma and it is being tested in interstitial cystitis patients, but its precise mechanism of action remains poorly understood. It is not clear whether BCG induces the release of a unique set of cytokines apart from its pro-inflammatory effects. Therefore, we quantified bladder inflammatory responses and alterations in urinary cytokine protein induced by intravesical BCG and compared the results to non-specific pro-inflammatory stimuli (LPS and TNF- $\alpha$ ). We went further to determine whether BCG treatment alters cytokine gene expression in the urinary bladder.
\end{abstract}

Methods: C57BL/6 female mice received four weekly instillations of BCG, LPS, or TNF- $\alpha$. Morphometric analyses were conducted in bladders isolated from all groups and urine was collected for multiplex analysis of 18 cytokines. In addition, chromatin immune precipitation combined with real-time polymerase chain reaction assay (CHIP/Q-PCR) was used to test whether intravesical BCG would alter bladder cytokine gene expression.

Results: Acute BCG instillation induced edema which was progressively replaced by an inflammatory infiltrate, composed primarily of neutrophils, in response to weekly administrations. Our morphological analysis suggests that these polymorphonuclear neutrophils are of prime importance for the bladder responses to BCG. Overall, the inflammation induced by BCG was higher than LPS or TNF- $\alpha$ treatment but the major difference observed was the unique granuloma formation in response to BCG. Among the cytokines measured, this study highlighted the importance of IL-I $\beta$, IL-2, IL-3, IL-4, IL-6, IL- I0, IL- I7, GM-CSF, KC, and Rantes as discriminators between generalized inflammation and BCG-specific inflammatory responses. CHIP/Q-PCR indicates that acute BCG instillation induced an up-regulation of IL-17A, IL-17B, and IL-I7RA, whereas chronic BCG induced IL-17B, IL-I7RA, and IL-I7RB.

Conclusion: To the best of our knowledge, the present work is the first to report that BCG induces an increase in the IL-I 7 family genes. In addition, BCG induces a unique type of persisting bladder inflammation different from TNF- $\alpha$, LPS, and, most likely, other classical pro-inflammatory stimuli. 


\section{Background}

Intravesical Bacillus Calmette-Guerin (BCG) has been presented as a promising option for treatment of interstitial cystitis [1]. However, intravesical BCG is best known as the most effective agent for the treatment of high-grade superficial bladder cancer [2-4]. In this context, BCG is used to reduce both the recurrence rate of bladder tumor and to diminish the risk of its progression [2,3]. As an adjunct to transurethral resection, BCG is the treatment of choice for urothelial carcinoma in-situ (CIS) and is commonly used for recurrent or multi-focal Ta and high grade T1 bladder lesions $[5,6]$.

It is not clear how BCG alters the course of cystitis or cancer progression. Recently, however, the susceptibility to
BCG was correlated with polymorphisms of the human NRAMP1 gene [7], providing interesting insights into the complexity of the genomics of BCG immunotherapy [8]. One theory is that intravesical BCG corrects an aberrant immune imbalance in the bladder, leading to long-term symptomatic improvement [1].

Here, we explore the possibility that BCG causes an extensive local inflammatory reaction in the bladder wall [9]. Of this, the massive appearance of cytokines in the urine of BCG-treated patients stands out [9]. Activated lymphocytes and macrophages are the most likely sources of these cytokines, but at present, other cellular sources such as urothelial cells cannot be ruled out [9]. BCG is internalized and processed by neutrophils [10], professional anti-

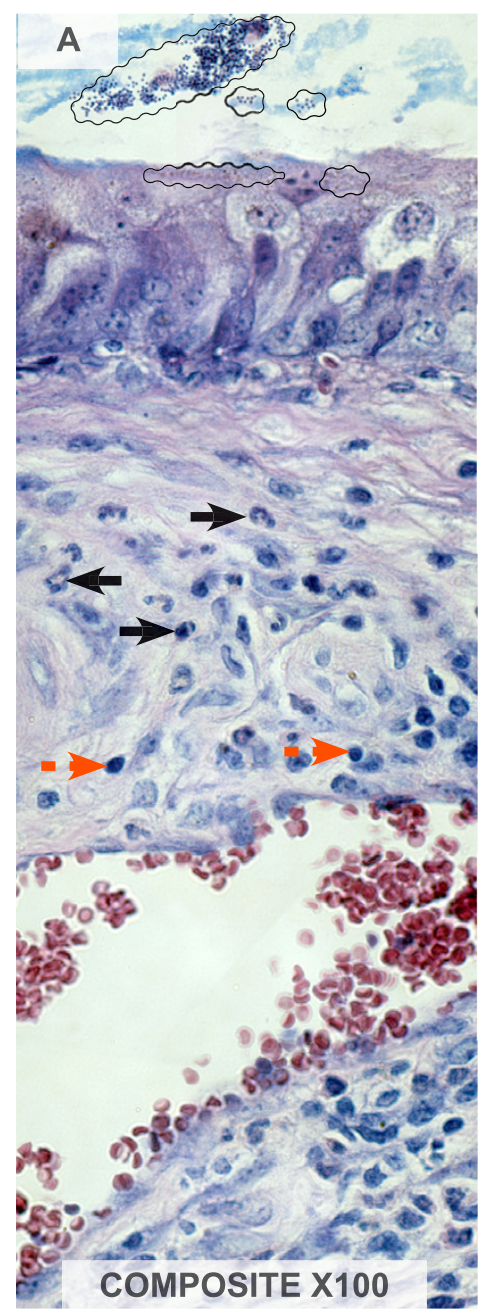

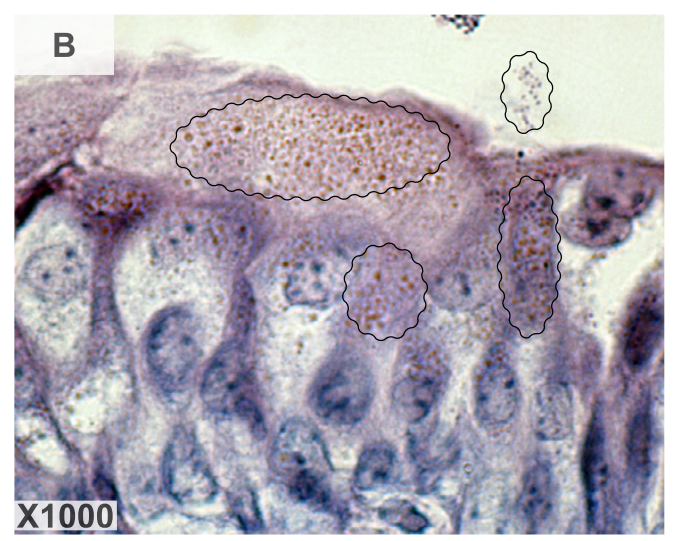
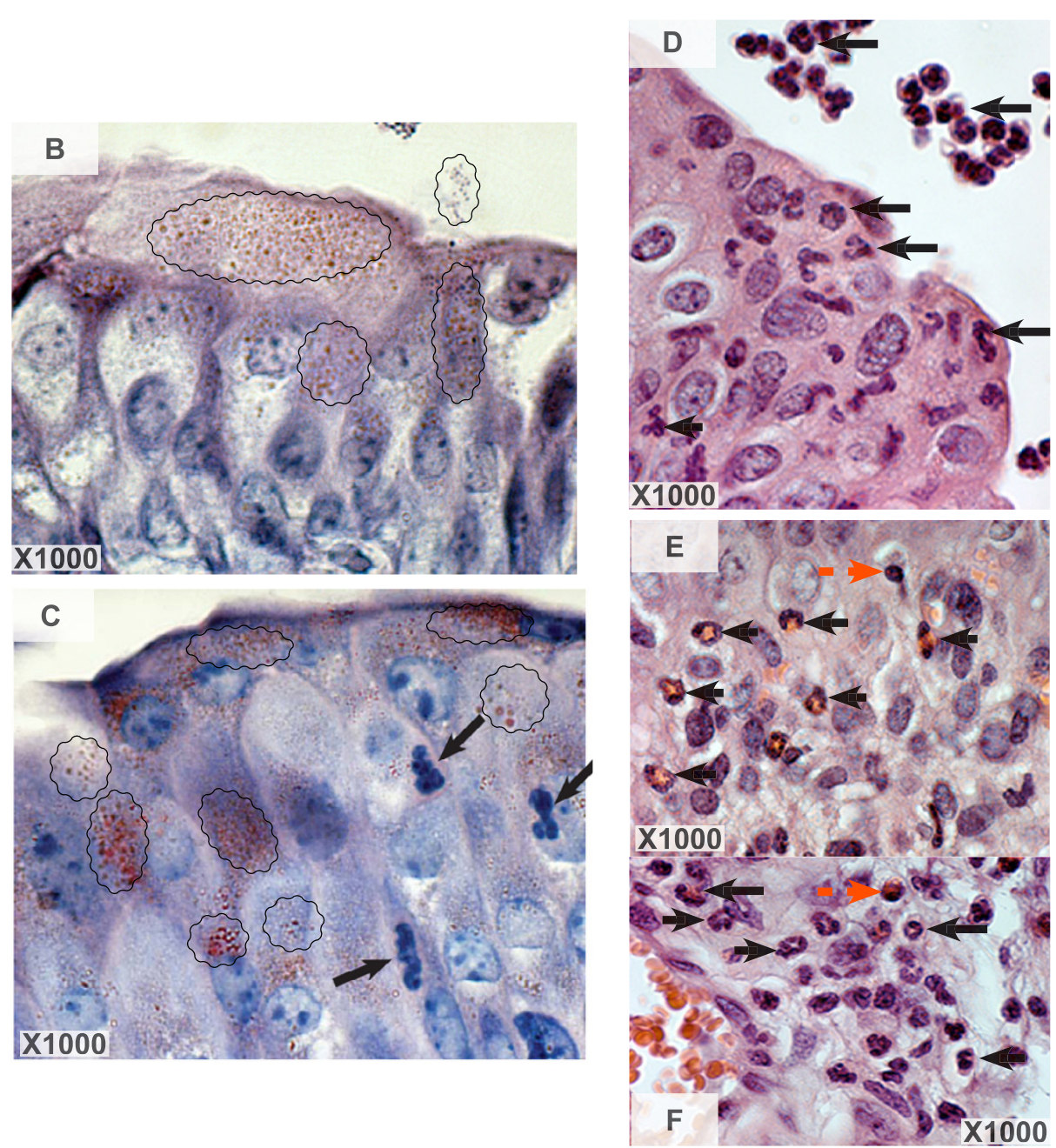

Figure I

BCG uptake by bladder urothelial cells. Representative photomicrographs indicating uptake of acid fast bacteria by the urothelial cells and infiltration of PMNs. Twenty four hours after bladder instillation with BCG, bladders were removed and stained with fast acid (A-C) or H\&E (D-F). Acid fast-positive bacteria were detected within umbrella cells and underlying urothelial cells, indicating that BCG is taken up by an apparent intact epithelium (Figure IA-C). Black wavy lines indicate areas containing fast acid-positive bacteria; black arrows indicate PMNs, and red arrow indicates lymphocytes. 


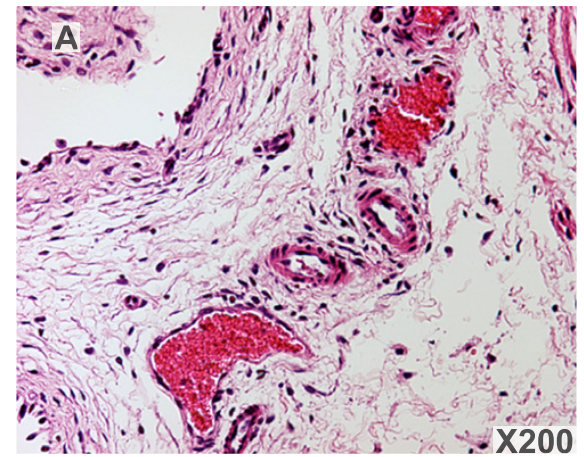

DAY 1

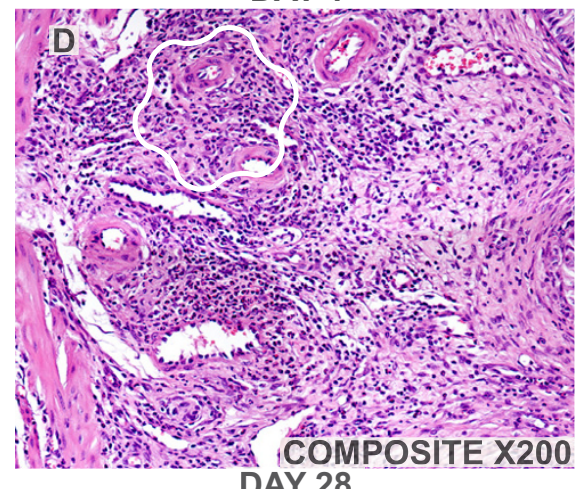

DAY 28

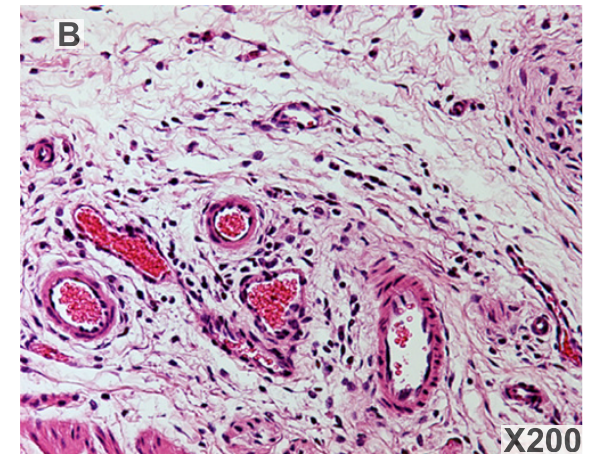

DAY 7

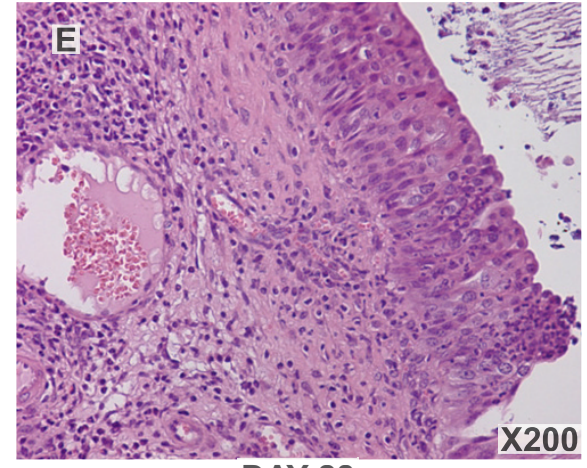

DAY 28

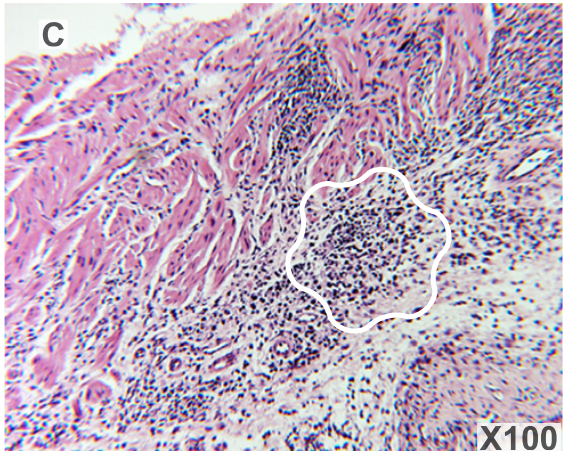

DAY 21

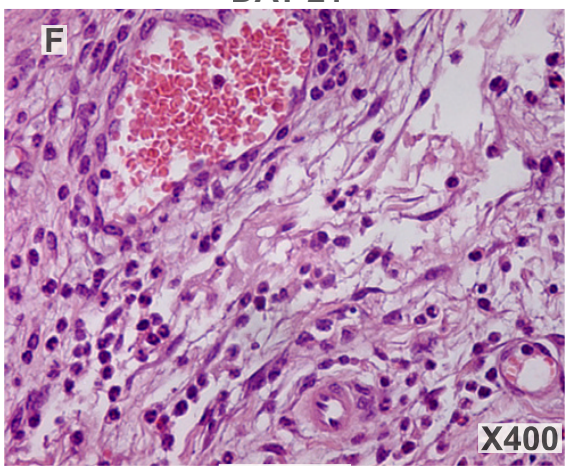

DAY 28

Figure 2

Time-course of bladder morphological alterations in response to weekly instillations with BCG. Representative photomicrographs of a time-dependent alteration of the mouse bladder secondary to intravesical instillation of BCG. Note, the intense edema observed days I-7 after the first instillation with BCG (A and B) and the subsequent invasion of inflammatory cells into the submucosa at day 7 (B) and a time-dependent invasion of the detrusor muscle at days 21 (C) and 28 (D-F). Granuloma-like formation is indicated by wavy white lines.

gen-presenting cells, and urothelial tumor cells, resulting in altered gene expression and secretion of particular cytokines [9]. It was suggested that the effectiveness of BCG treatment is determined by two processes: an inflammatory one, followed by a delayed type of hypersensitivity response [11]. Others proposed three distinct phases in the immune response to BCG. In phase 1, BCG adheres to the urothelium via interaction between the bacterial antigen 85 complex and fibronectin $[6,12]$ and urothelial cells. In addition to fibronectin, it has been suggested that toll-like receptors (TLRs) -2 and -4 , present in immune cells, mediate BCG-induced immune responses [13-15]. Once internalized, BCG is processed both by professional antigen-presenting cells and urothelial cells, resulting in an altered gene expression [9]. This phase corresponds to the early release of so-called inflammatory cytokines (IL1 , IL-6, and IL-8 in humans) which may be responsible for certain adverse effects. Phase 2 consists of recognition of bacterial antigens by CD4 lymphocytes, which release mainly IL-2 and IFN- $\gamma\left(\mathrm{TH}_{1}\right.$ response). This cell activation leads to phase 3 , which consists of amplification of cytotoxic-populations: CD8 T cells, gamma-delta lym- phocytes, macrophages, and natural killer (NK) cells. All these cells also release cytokines which then regulate BCG response [16].

More recently, studies have shown that mycobacterial DNA contains high amounts of CpG motifs. These CpG motifs induce tumor necrosis factor-related apoptosisinducing ligand (TRAIL) expression [17] and increase serum levels of mouse keratinocyte-derived chemokine (KC), a functional homolog of human interleukin IL-8 [18]. Urinary TRAIL levels were initially undetectable in BCG therapy patients, but levels increased after subsequent treatments. More importantly, patients that responded to BCG therapy had significantly higher urine TRAIL levels, which killed bladder tumor cells in vitro versus non-responders. Given these data, it was proposed that TRAIL also plays a role in BCG-induced anti-tumor effects [17].

Nevertheless, BCG's mechanism of action remains poorly understood. Although systemic reactions have been reported, a likely scenario is that exposure to BCG results 
Table I: Q-PCR PRIMERS

\begin{tabular}{|c|c|c|c|}
\hline ACCESSION NUMBER & SYMBOL & FORWARD PRIMER & REVERSE PRIMER \\
\hline NM 00997I & G-csf & tgtcctcacaggaacgaagtc & cttcctcctgcctcctctg \\
\hline NM 009969 & GM-csf & gccacagttggaaggcagta & aaatataatggtccctatcagtagaaa \\
\hline NM 008337 & $\mathrm{IFNg}$ & agacttctgggcgtcctacc & tgaccaagcctttcataagatg \\
\hline NM 010548 & IL- 10 & gctgagactttcgctcctctc & agctccaaggcacctgttc \\
\hline NM 00835I & IL-I $2 \mathrm{a}$ & attgccacggtttcctctc & cctccttccctcctctgttc \\
\hline NM 008352 & $\mathrm{IL}-\mathrm{I} 2 \mathrm{~b}$ & tcaccttctctgggcatttc & gctattgggcatgcagtgag \\
\hline NM 00836I & IL-Ib & ttcccaatccctcaacagtc & atgttctggagcaggcagtg \\
\hline NM 008366 & IL-2 & acaatgtgggtgggtcactg & tgtcaagatagccaggaagacac \\
\hline NM 021283 & IL-4 & ggctttcctctttcccactc & agccgccatgagagctaag \\
\hline NM 031168 & IL-6 & gctgggattcttcaccactg & tgacttgtcctgagacctgatg \\
\hline NM 008176 & $\mathrm{KC}(\mathrm{Cxcll})$ & tcgtctttcatattgtatggtcaac & cgagacgagaccaggagaaac \\
\hline NM 011337 & Mipla (Ccl3) & ctccctcccagttggtcac & ttaaagggcatatttattacttctctg \\
\hline NM 013653 & Rantes (Ccl5) & cctattatgagccggcagag & gggtgccgtagatcattctg \\
\hline NM 013693 & TNFa & tcaggttgcctctgtctcag & gctctgtgaggaaggctgtg \\
\hline NM 010552 & ILI7a & tcatttcctcctggcttttg & tgagcttcccagatcacaga \\
\hline NM 019508 & ILI7b & ctttccccactctcccagac & caaccaacccaacgccttac \\
\hline NM 145837 & ILI7d & ggccaaaacacacacaggta & ccttggtcagaaccgtagga \\
\hline NM 080729 & ILI7e & gagtgggggtctcagctaca & gatggggctctgtaacctttc \\
\hline NM 145856 & ILI7f & acttcagaggcgaaggcata & tgactgtgcatgttggattt \\
\hline NM 008359 & ILI7ra & tttcatctttccagcctcct & ggagcccagttgtctgtgag \\
\hline NM 134437 & ILI7rd & cagaagcgttggtagcagaa & ccactgagacagcaccagaa \\
\hline
\end{tabular}

in a local immune response and massive inflammation [6], which makes it difficult to analyze the direct effects of BCG on the urinary bladder in BCG treated patients. Therefore, we propose to characterize in $\mathrm{C} 57 \mathrm{BL} / 6$ mice, bladder responses to intravesical BCG therapy. C57BL/ 6 mice were chosen not because of the Th1 biased response of this strain [19], but because it will permit comparisons with other animal models of bladder inflammation already developed in C57BL/6 background [20,21].

In this first manuscript, we propose to determine whether the intact mouse urinary bladder takes up BCG, the timedependent morphological alterations, and urinary cytokine release in response to intravesical BCG. These effects were compared to those elicited by other inflammatory stimuli (LPS and TNF- $\alpha$ ) to differentiate BCG-specific effects from generalized inflammatory reactivity.

\section{Results}

\section{BCG uptake by bladder urothelial cells}

Twenty-four hours after instillation of BCG into the mouse bladder, fast acid-positive bacteria were detected within umbrella cells and underlying urothelial cells, indicating that BCG is taken up by an apparent intact epithelium (Figure 1A-C). The local inflammatory reaction in response to BCG was characterized by an initial increase in blood flow, enhanced vascular permeability characterized by edema, and an influx of different effector cells. At this time point, vasodilation was evident and inflammatory cells (PMNs and lymphocytes) populated the submucosal layer (Figure 1A). Interestingly, some intraepithelial PMNs were also observed nearby urothelial cells containing BCG (Figure 1C). PMNs invaded predominantly the sub-urothelial mucosal layer (Figure 1A and $1 \mathrm{E})$, and some inflammatory cells were also observed outside the urothelium, in the bladder lumen (Figure 1D).

In early time points, BCG induced an acute bladder inflammation characterized by a strong vascular component and edema. Characteristic photomicrographs of BCG-induced bladder inflammation exemplify the trend from an intense edema observed on days 1 and 7 (Figures 2A-B), and a gradual substitution of the edema by an influx of PMNs and other inflammatory cells (Figure 2CF). Migrating inflammatory cells were initially observed in submucosa (Figure 2A-B) and gradually invaded the detrusor muscle (Figure 2C). From days 21 to 28, in addition to PMNs (Figure 2C-E), there was a substantial presence of monocyte-macrophages (Figure 3). During chronic inflammation, several spots presented granuloma-like formations [22] (Figure 2C and 3).

All three stimuli induced bladder inflammation. BCG was the strongest stimulus for PMN migration (Figure 4), whereas edema appeared as an acute response to all stimuli (Figure 5). Interestingly, the area of edema formation in response to BCG was biphasic, appearing as early as twenty four hours after BCG instillation and declining at fourteen days despite weekly instillations with BCG (Figure 5). 


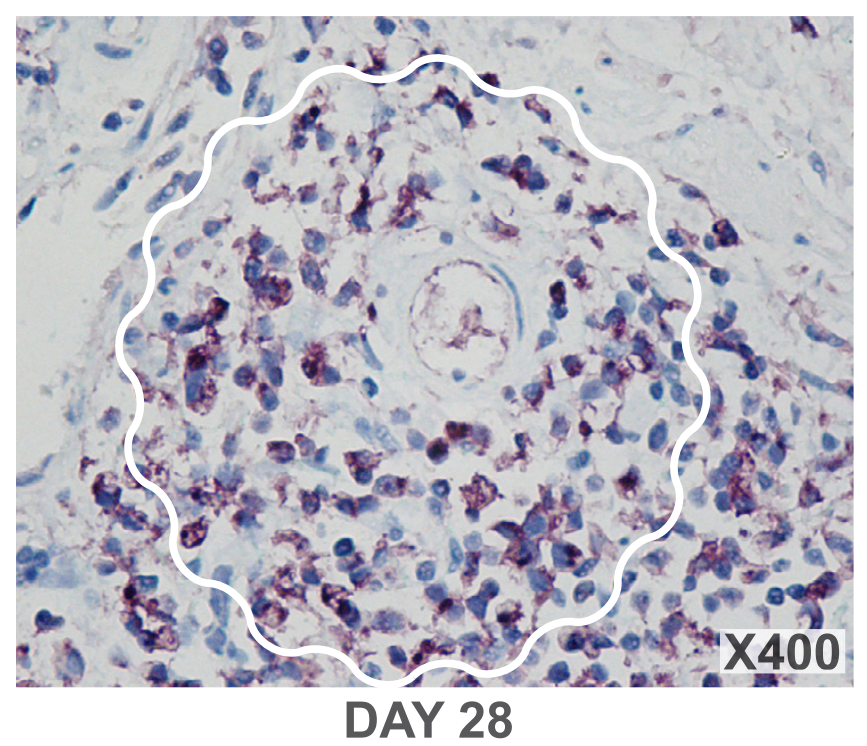

Figure 3

Granuloma-like formation is indicated by wavy white lines. The presence of monocyte/macrophages was determined by IHC immunohistochemistry with rat anti-mouse macrophage monocyte antibody and secondary antibody anti-mouse Fab$\operatorname{HRP}(G)$.

Next, we determined how long the inflammatory response to BCG was maintained. For this purpose, mice that received weekly instillations of BCG for 4 weeks had the treatment discontinued (day zero), and were examined weekly up to 5 weeks for the presence of bladder inflammation. The degree of inflammation observed at the end of 4 weekly BCG instillations (day zero) was maintained up to three weeks following discontinuation of the therapy. Both the edema and PMNs were reduced at 4 weeks whereas the vasodilation was maintained for the whole 5 weeks of observation (data not shown).

Together, these results indicate that bladder instillation with BCG or TNF- $\alpha$ induce a classical inflammatory response, as previously described for LPS $[23,24]$. However, relative to LPS and TNF- $\alpha$, bladder responses to BCG produce a higher PMN influx, with cells remaining well after discontinuation of the treatment. Additionally, BCG was the only agent capable of inducing formation of granuloma-like structures.

\section{Urinary cytokine levels}

All three stimuli induced a time-dependent increase in urinary cytokine levels (Figures 6, 7, 8, 9, and 10). Overall, BCG induced the most comprehensive cytokine responses, followed by LPS and TNF- $\alpha$. Additionally, some cytokine levels were altered acutely, whereas others were elevated only after chronic stimulation (detailed below). Cytokine induction relative to baseline levels was calculated and ranked for each inflammatory agent (Table 2). Consistent with the rapid and massive neutrophil infiltrates observed histologically, relative induction of $\mathrm{KC}$ was highest in response to BCG, reaching 47,000 times the control level. In addition to KC, BCG induced the release of: MIP- $1 \alpha$, IL- $1 \alpha$, RANTES, IL-6, G-CSF, IL-1 $\beta$, IL17 , IL-4, IL-12(p70), and GM-CSF. In contrast to BCG, the unique cytokine induced by LPS was IL- $1 \beta$, and MIP- $1 \alpha$ reached the highest peak in response to acute LPS (Table 2 ). In addition to MIP-1 $\alpha$, LPS induced the release of the following cytokines (listed in order of induction levels): IL- $\alpha$, G-CSF, KC, IL- $1 \beta$, IFN $\gamma$, RANTES, IL-4, IL-5, IL-12 (p70), TNF $\alpha$, IL-17, and IL-10. Finally, G-CSF was found

Table 2: Peak urinary cytokine levels in response to BCG, TNF, and LPS calculated as percent of baseline

\begin{tabular}{|c|c|c|c|c|c|}
\hline \multicolumn{2}{|c|}{ BCG } & \multicolumn{2}{|c|}{ TNF } & \multicolumn{2}{|c|}{ LPS } \\
\hline $\mathrm{KC}$ & 47474 & G-CSF & 2424 & MIP-Ia & 732446 \\
\hline MIP-Ia & 7314 & KC & 2305 & IL-Ia & 10048 \\
\hline IL-Ia & 6422 & IL-Ia & 1210 & G-CSF & 5045 \\
\hline RANTES & 4732 & IL-6 & 729 & KC & 4186 \\
\hline IL-6 & 4591 & IL-2 & 410 & $I I-I b$ & 1064 \\
\hline G-CSF & 2244 & IL-17 & 334 & IFN-g & 902 \\
\hline$I I-I b$ & 2236 & MIP-Ia & 251 & RANTES & 751 \\
\hline IL-17 & 1469 & II-5 & 226 & IL-4 & 716 \\
\hline IL-4 & 991 & RANTES & 226 & II-5 & 446 \\
\hline IL-I 2 (p70) & 540 & IL-4 & 214 & IL-I $2(p 70)$ & 393 \\
\hline GM-CSF & 533 & IFN-g & 186 & TNF-a & 387 \\
\hline IFN-g & 485 & II-Ib & 120 & IL-I7 & 387 \\
\hline $11-5^{\circ}$ & 473 & IL-I2(p70) & 119 & IL- 10 & 345 \\
\hline IL-2 & 410 & GM-CSF & 118 & IL-2 & 255 \\
\hline IL-3 & 382 & TNF-a & 118 & IL-I2(p40) & 248 \\
\hline TNF-a & 349 & IL-3 & 115 & GM-CSF & 235 \\
\hline IL-I2(p40) & 338 & IL-I2(p40) & 111 & IL-3 & 206 \\
\hline IL-I0 & 235 & IL-10 & 106 & IL-6 & 173 \\
\hline
\end{tabular}




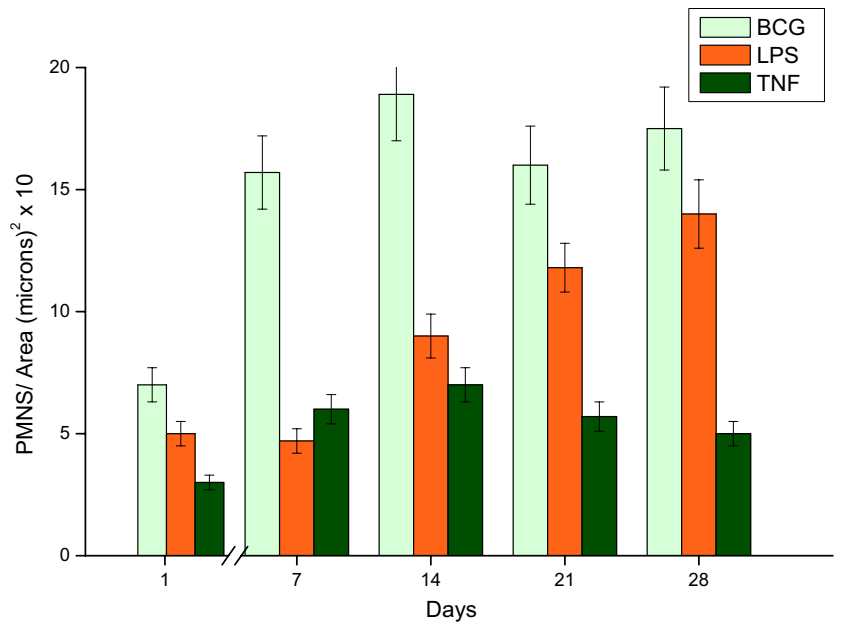

Figure 4

PMNS. Mouse bladder morphological analysis in response to weekly instillations of BCG, LPS, and TNF- $\alpha$. The time-course of inflammation was characterized by the number of polymorphonuclear leukocytes [PMNs] infiltrating the urinary bladder.

to be the highest cytokine in response to TNF- $\alpha$. In addition to G-CSF, TNF- $\alpha$ induced the following cytokines (listed in order of induction levels): KC, IL-1 $\alpha$, IL-6, IL-2, IL-17, MIP- $1 \alpha$, IL-5, RANTES, IL-4, IFN- $\gamma$, and IL-1 $\beta$ (Table 2).

Both pro-inflammatory and anti-inflammatory cytokines were detected in the mouse urine following inflammation induced by BCG, TNF- $\alpha$, and LPS. However, IL-17 was induced primarily in response to BCG (Figure 9). In addition, we confirmed previous reports indicating that certain cytokines, such as IL-12 represented the early responses of the urinary bladder to BCG [25]. In the present study, this cytokine was the first to be released and may reflect a direct stimulation of bladder resident cells, whereas cytokines induced subsequent to this acuteresponse phase may be the result of secondary mediator synthesis by migrating inflammatory cells. In addition to IL-12, other cytokines, like GM-CSF and IL-2, represent an early response to all three agents.

To better characterize BCG-specific responses, the timecourses of cytokine levels were mathematically modeled, and time-dependent inductions of the 3 agents compared. The time-course of IL- $1 \beta$, IL-2, IL-3, IL-4, IL-6, IL-10, IL12p70, IL-17, GM-CSF, KC, and RANTES induction discriminate between the effects of $\mathrm{BCG}$ relative to the inflammatory responses obtained with LPS and TNF- $\alpha$ (Table 3).

Next, we used CHIP/Q-PCR to investigate whether acute BCG (24 hours after a single instillation) and chronic BCG ( 7 days after four weekly instillations) would also alter cytokine gene expression in the whole mouse bladder. With the exception of IL-6, KC, and MIP1 $\alpha$, acute BCG instillation induced an increased expression of all other cytokine and chemokine genes tested (Figures 11 and 12). Chronic BCG instillation induced increased expression of all cytokine genes measured with the exception of IL-6 (Figures 11 and 12). In addition, particular attention was paid to the IL-17 gene family since IL-17A protein was one of the cytokines that discriminated between BCG and the other pro-inflammatory stimuli (Table 3). CHIP/Q-PCR results indicate a differential up regulation of this family between acute and chronic BCG (Figure 13).

\section{Discussion \\ BCG uptake by bladder urothelial cells}

Our results indicate that BCG is taken up by an apparent intact urothelium and accumulates within urothelial cells. Others have shown that E. coli is present in pod-like

Table 3: Discriminators of BCG effects versus TNF and LPS over time.

\begin{tabular}{cll}
\hline Analyte & p value \\
\hline GM-CSF & 0.001 \\
IL-I beta & 0.007 \\
IL-2 & 0.006 \\
IL-3 & 0.032 \\
IL-4 & 0.016 \\
IL-6 & 0.000 \\
IL-10 & 0.001 \\
IL-I2p70 & 0.012 \\
IL-I7 & 0.002 \\
KC & 0.018 \\
RANTES* & 0.001
\end{tabular}

\footnotetext{
Urinary cytokines response over time was determined using a mixed modeling approach, according to the following equation: Cytokine Level $=(\mathrm{a})$ * Time + (b) Trx * Time, where Trx is BCG vs LPS \& TNF-Alpha. A variance component covariance matrix was used to account for the correlation structure inherent in longitudinal measurements of cytokines.*Time squared interaction.
} 


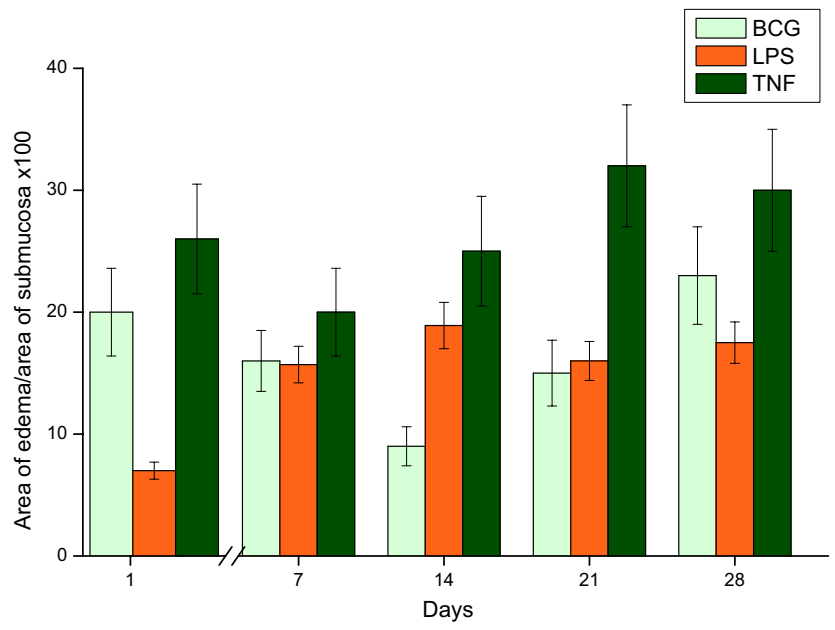

Figure 5

Edema. Mouse bladder morphological analysis in response to weekly instillations of BCG, LPS, and

TNF- $\alpha$. The time-course of inflammation was characterized by the edema in the urinary bladder.

bulges on the urothelial bladder surface, which represents a reservoir for bacteria and explains the persistence of bladder infections [26]. It remains to be determined whether this mechanism applies to BCG. Nevertheless, the intact mouse urothelium is highly BCG responsive and, as such, is a useful model to study mechanisms and receptors that modulate the $\mathrm{BCG}$ uptake by the urinary bladder. In this context, previous results from our laboratory indicate that LPS-fluorescein is taken up by the intact mouse bladder urothelium, provokes bladder inflammation, and it is systemically distributed [23]. Together, our findings indicate that although the urothelium present a tightly controlled permeability, certain bacteria and toxins find their way to penetrate this layer and to cause inflammation.

\section{Morphological alterations - PMNs infiltration}

Our results indicate that bladder inflammation is part of the response to intravesical BCG therapy (Figures 1, 2, 3). This inflammation is characterized by a rapid onset of edema and a graded and massive migration of inflammatory cells (lymphocytes, PMNs and monocytes/macrophages) initially into the lamina propria, which spreads to detrusor muscle as well (Figure 1). In humans, intravesical therapy induces a well-described T-lymphocyte predominant inflammatory infiltrate in the bladder wall $[27,28]$, and it is proposed that helper and cytotoxic T cells and, most probably, natural killer cells are necessary for antitumor effects and the Th-1 biased immune response that underlines BCG therapy [29]. Although BCG-treated mouse bladder also exhibited lymphocytic infiltrates during the acute response and macrophages during the late phase responses (Figure 3), PMNs were overwhelmingly present, suggesting the initial response is dominated by these cells. Indeed, our histological results (Figure 1) and the consequent morphological analysis (Figure 4) suggest that PMNs are of prime importance in the model under investigation. This cell-type is a bona fide inflammatory cell, and it accounts for more than $90 \%$ of the urinary cellular infiltrate early after BCG-mediated immune responses. Indeed, Siracusano et al confirmed that in humans, following intravesical BCG prophylaxis, a large number of PMNs transmigrated through the urothelium and are found isolated or adherent to detached urothelial cells in the urine [30]. In addition, flow cytometry analysis of fresh urine from patients receiving intravesical BCG revealed TRAIL-expressing neutrophils [17]. Others have shown in mice that PMNs migrate into the bladder after intravesical BCG instillation, and that depletion of PMNs from tumor-bearing mice completely abrogated antitumor efficacy of BCG [31]. In vivo, depletion of PMNs from BCG-treated mice significantly impaired CD4(+) Tcell trafficking to the bladder [31]. Furthermore, PMNs isolated from the urine of BCG-treated patients were a major source of IL-8, growth-related oncogene-alpha, MIP-1 $\alpha$, and inflammatory cytokine migration inhibitory factor [31]. Therefore, our results agree with other findings indicating that PMNs direct the migration of effector cells to the bladder and are indispensable for effective tumor immunotherapy $[17,30,31]$.

Subsequent to the initial response, macrophages localized in close proximity to neutrophils in a granuloma-like structure that occurred in the mouse bladder over time (Figure 3). The granuloma is a hallmark of Mycobacterium-induced pathology $[22,32,33]$. BCG-induced granuloma seems to depend on TNF- $\alpha$ release $[34,35]$. Indeed, transgenic mice expressing high serum levels of sTNFR1, capable of neutralizing all circulating TNF, failed to develop differentiated granulomas and bactericidal mechanisms, and succumbed to BCG infection [36]. However, in our studies, chronic bladder instillation with TNF- $\alpha$ alone was not enough to induce granuloma formation. The latter could be due to a reduced uptake of TNF- $\alpha$ by the urinary bladder, or that other factors are necessary for the development of granuloma. Indeed, recent results indicate that granuloma formation depends primarily on the presence of transmembrane TNF- $\alpha$ [35].

Although systemic reactions (evolution of cellular immune response or systemic production of cytokines and oxygen free radicals) have been reported in response to bladder instillation with BCG, a likely scenario is that exposure to BCG results in a massive local inflammatory response [37]. Correspondingly, in the present mouse model, BCG induces a stronger PMN infiltration than 

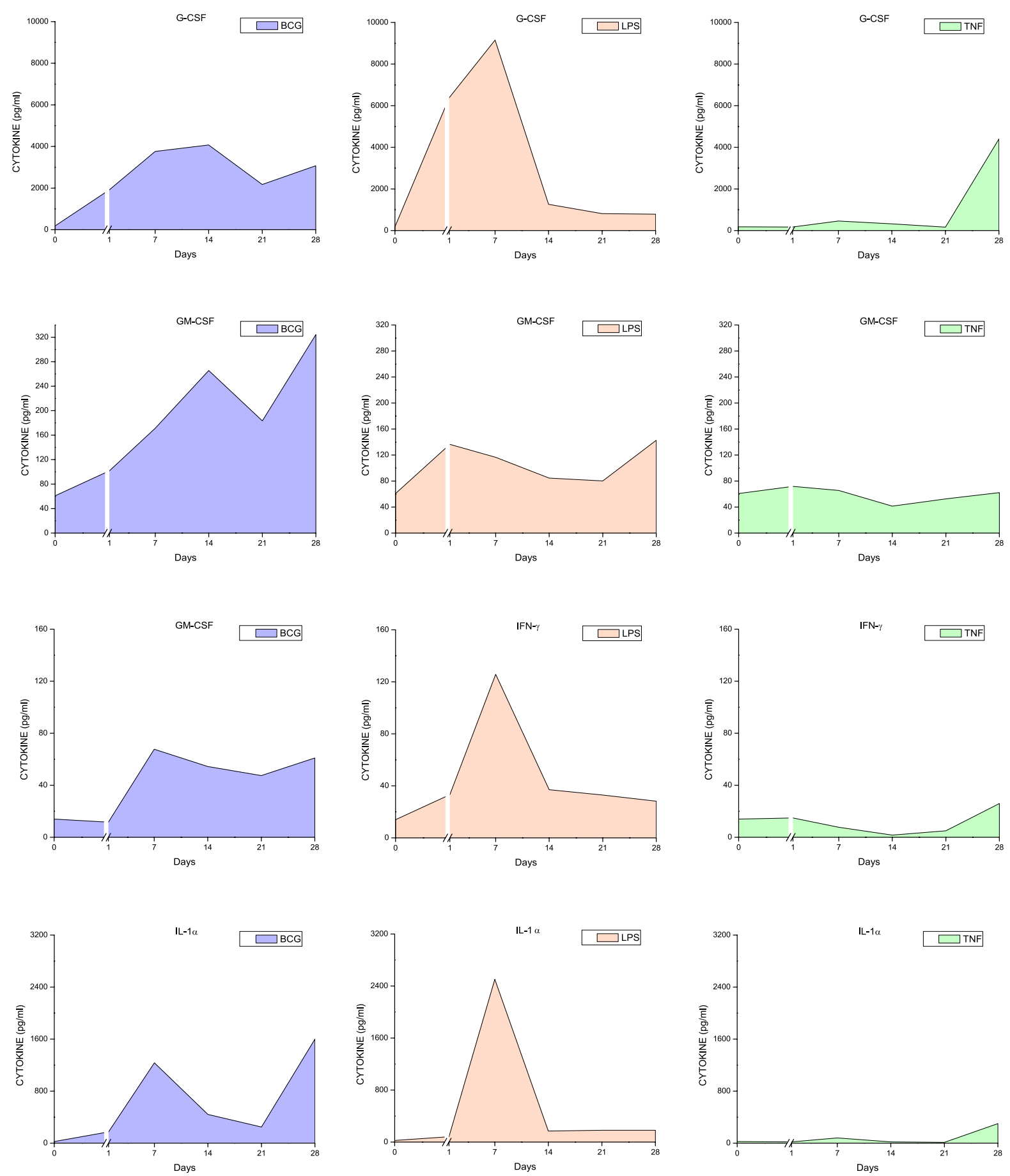

Figure 6

Urinary cytokine levels $(\mathrm{pg} / \mathrm{ml})$ in response to weekly instillations of BCG, TNF- $\alpha$, and LPS into the bladder of female mice. Cytokine measurements were performed using fifty microliters of each sample and done in duplicate on the Luminex 100 (Bio-Rad Laboratories, Hercules, CA) using a Bio-Plex Mouse Cytokine I8-Plex (catalog \#I7I-FII I8I, BioRad). The concentrations of analytes in these assays were quantitated using a standard curve. A regression analysis was performed to derive an equation that was then used to predict the concentration of the unknown samples. Time zero indicates basal levels of cytokines before instillation of any agent. A break at day I was added to each graph to contrast the altered cytokine levels when compared to basal levels. 

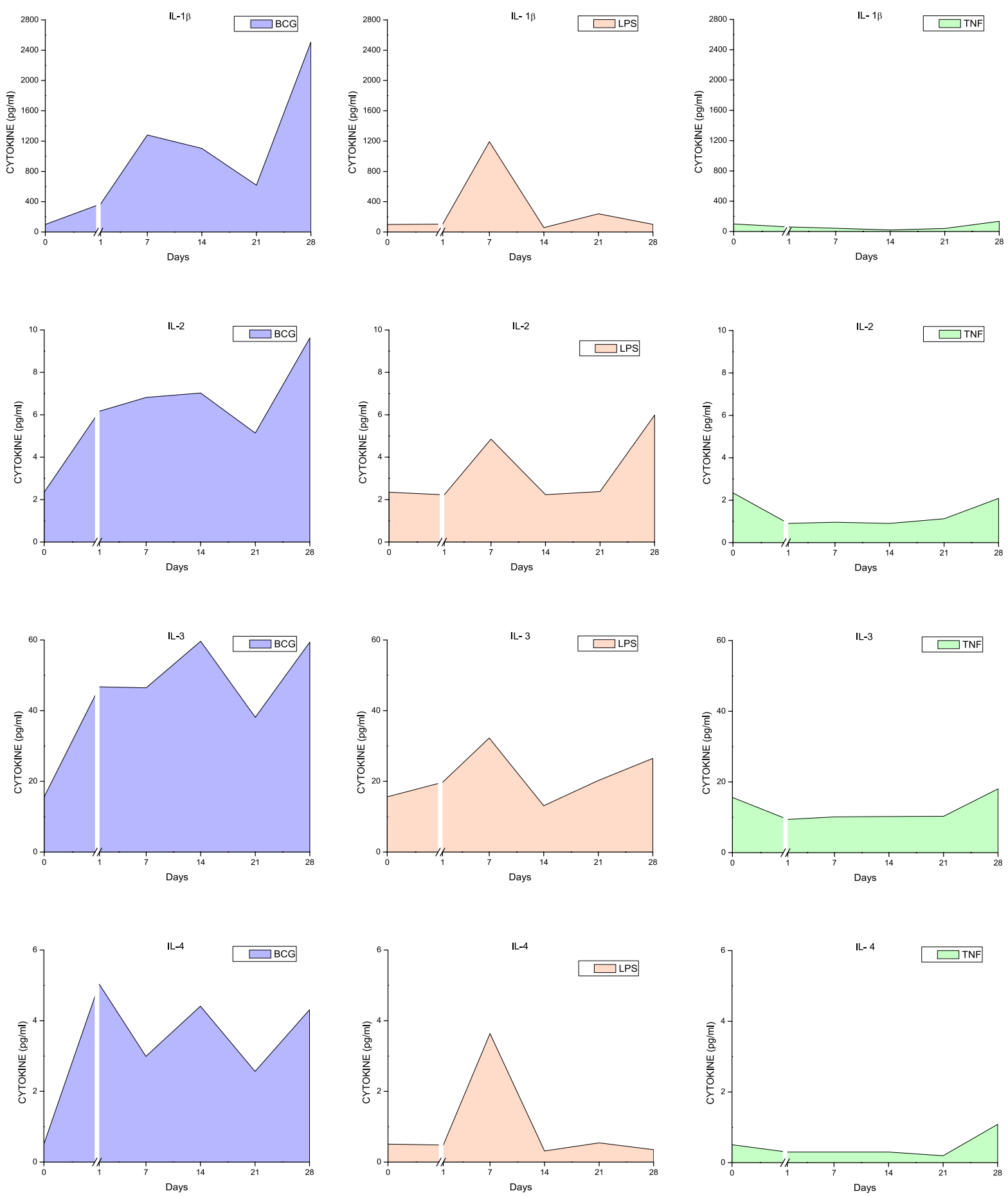

Figure 7

Urinary cytokine levels $(\mathrm{pg} / \mathrm{ml})$ in response to weekly instillations of BCG, TNF- $\alpha$, and LPS into the bladder of female mice. Cytokine measurements were performed using fifty microliters of each sample and done in duplicate on the Luminex 100 (Bio-Rad Laboratories, Hercules, CA) using a Bio-Plex Mouse Cytokine I8-Plex (catalog \#I7I-FII I8I, BioRad). The concentrations of analytes in these assays were quantitated using a standard curve. A regression analysis was performed to derive an equation that was then used to predict the concentration of the unknown samples. Time zero indicates basal levels of cytokines before instillation of any agent. A break at day I was added to each graph to contrast the altered cytokine levels when compared to basal levels. 

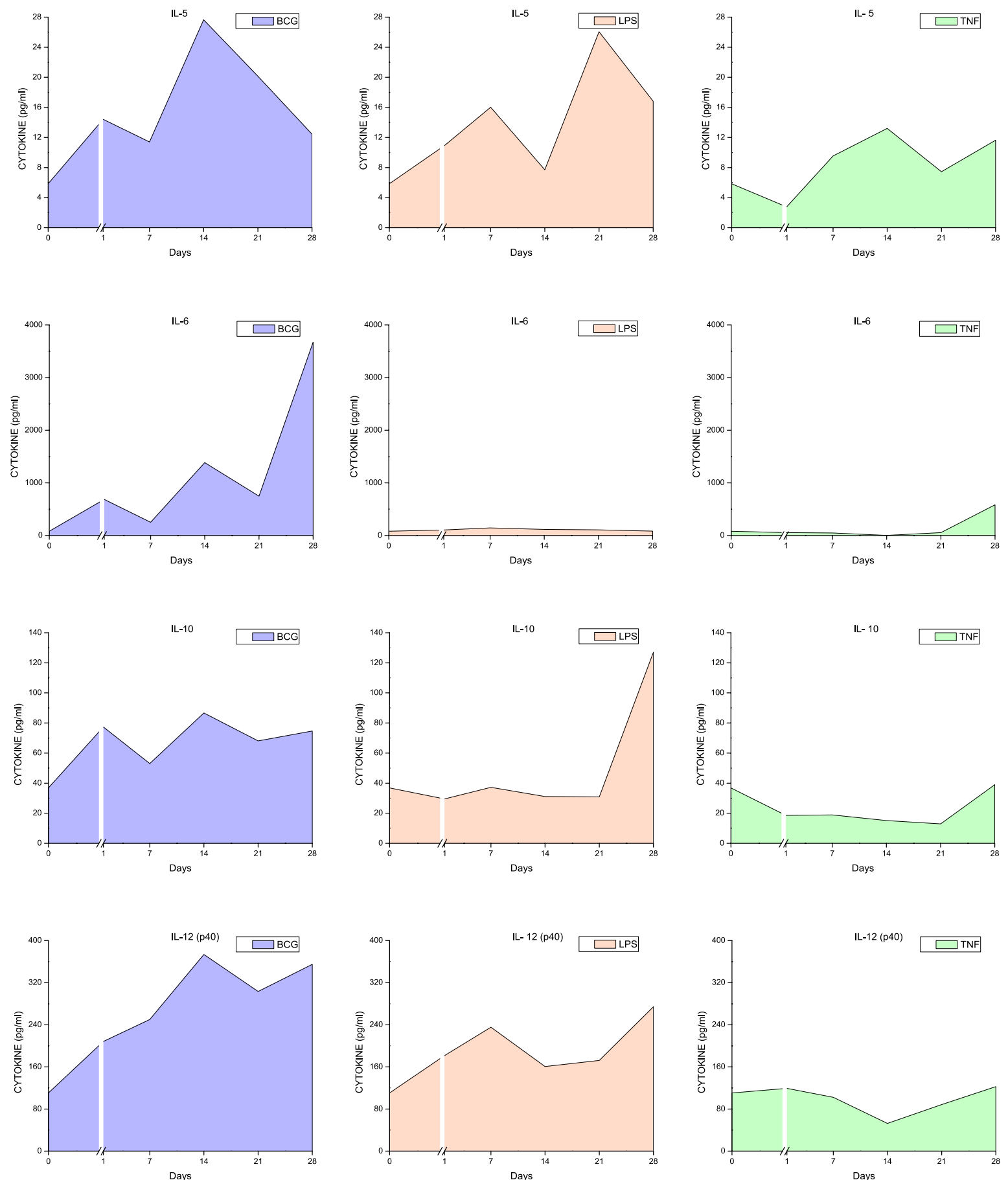

\section{Figure 8}

Urinary cytokine levels $(\mathrm{pg} / \mathrm{ml})$ in response to weekly instillations of BCG, TNF- $\alpha$, and LPS into the bladder of female mice. Cytokine measurements were performed using fifty microliters of each sample and done in duplicate on the Luminex 100 (Bio-Rad Laboratories, Hercules, CA) using a Bio-Plex Mouse Cytokine I8-Plex (catalog \#I7I-FII I8I, BioRad). The concentrations of analytes in these assays were quantitated using a standard curve. A regression analysis was performed to derive an equation that was then used to predict the concentration of the unknown samples. Time zero indicates basal levels of cytokines before instillation of any agent. A break at day I was added to each graph to contrast the altered cytokine levels when compared to basal levels. 

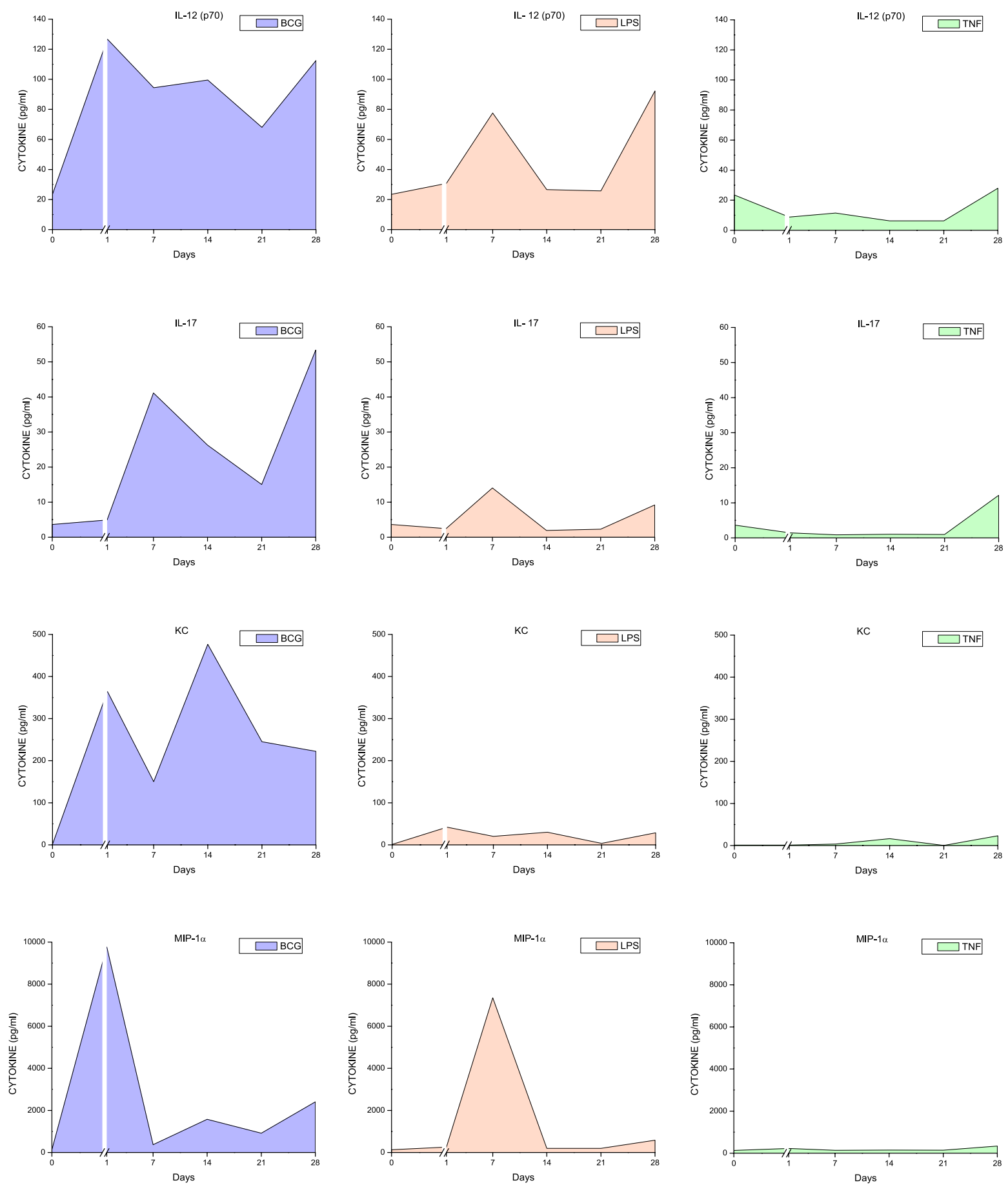

\section{Figure 9}

Urinary cytokine levels $(\mathrm{pg} / \mathrm{ml})$ in response to weekly instillations of BCG, TNF- $\alpha$, and LPS into the bladder of female mice. Cytokine measurements were performed using fifty microliters of each sample and done in duplicate on the Luminex 100 (Bio-Rad Laboratories, Hercules, CA) using a Bio-Plex Mouse Cytokine I8-Plex (catalog \#I7I-FII I8I, BioRad). The concentrations of analytes in these assays were quantitated using a standard curve. A regression analysis was performed to derive an equation that was then used to predict the concentration of the unknown samples. Time zero indicates basal levels of cytokines before instillation of any agent. A break at day I was added to each graph to contrast the altered cytokine levels when compared to basal levels. 

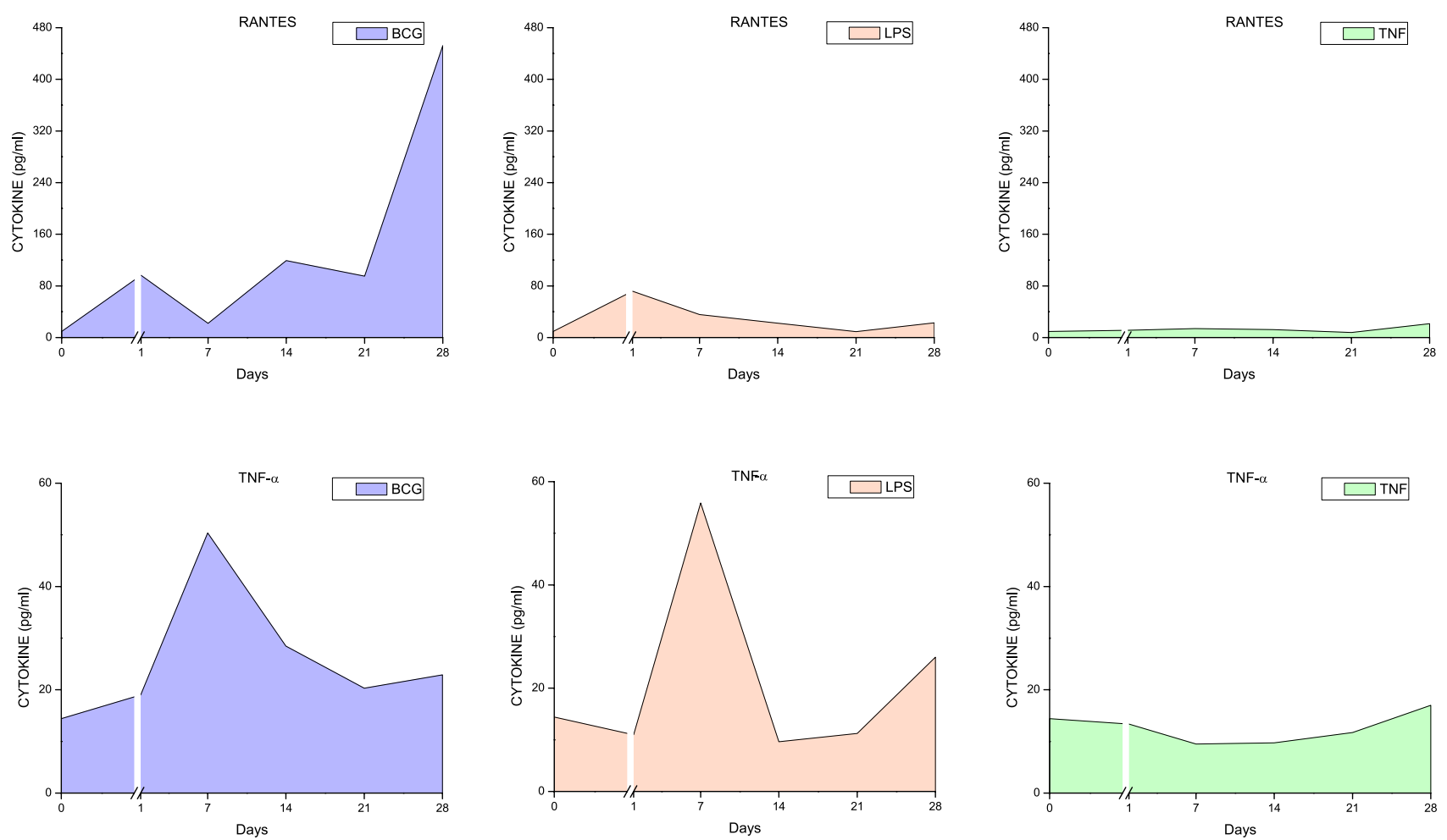

\section{Figure 10}

Urinary cytokine levels $(\mathrm{pg} / \mathrm{ml})$ in response to weekly instillations of BCG, TNF- $\alpha$, and LPS into the bladder of female mice. Cytokine measurements were performed using fifty microliters of each sample and done in duplicate on the Luminex 100 (Bio-Rad Laboratories, Hercules, CA) using a Bio-Plex Mouse Cytokine I8-Plex (catalog \#I 7I-FI I I 8I, BioRad). The concentrations of analytes in these assays were quantitated using a standard curve. A regression analysis was performed to derive an equation that was then used to predict the concentration of the unknown samples. Time zero indicates basal levels of cytokines before instillation of any agent. A break at day I was added to each graph to contrast the altered cytokine levels when compared to basal levels.

TNF- $\alpha$ and LPS. Additionally, granuloma formation was only observed in response to chronic BCG instillation.

\section{LPS and TNF as pro-inflammatory stimuli}

The rationale for the use of LPS was that the bladder inflammatory responses to this bacterial toxin have been well characterized in our laboratory. We have presented evidence that LPS induces a time-dependent cystitis [24] concomitantly with the release of cytokines [23]. In contrast, although there is strong circumstantial evidence indicating that TNF- $\alpha$ plays a fundamental role in bladder inflammation [21], to our knowledge, the present study is the first to use intravesical TNF- $\alpha$ as a model for cystitis. TNF- $\alpha$, at the concentration used in this study, was the weakest inducer of cytokine release (Figures $6,7,8,9,10$ ). Although the concentration of TNF- $\alpha$ employed in this study was at least 100-fold higher than the one used to provoke neutrophil migration in the mouse skin [38], it is possible that much higher concentrations of TNF- $\alpha$ would lead to levels of urinary cytokines comparable to LPS. In the context of TNF- $\alpha$, it seems that the regimen applied in this study, allowing at least 7 days between bladder instillation and urine collection, decreased the possible bias of TNF- $\alpha$ instillation on its urinary levels.

\section{BCG-induced cytokine release}

Keratinocyte-derived chemokine (KC; CXCl1; or Gro- $\alpha$ ) levels were the most altered by BCG (Table 2). As the mouse does not produce IL- 8 , measurement of mouse KC, a functional homolog of human IL-8 [18], could give us some information regarding a role of this pro-inflammatory cytokine in mediating BCG responses. $\mathrm{KC}$ is a potent neutrophil chemoattractant that can be secreted by neutrophils, epithelial cells, endothelial cells, smooth muscle cells, fibroblasts, macrophages, platelets, and lymphocytes [39]. The main stimuli for KC production are IL1 , TNF- $\alpha$, bacterial products, radical oxygen species, and LPS, as well as the T cell products, such as IL- 4 and IFN- $\gamma$ [39]. 


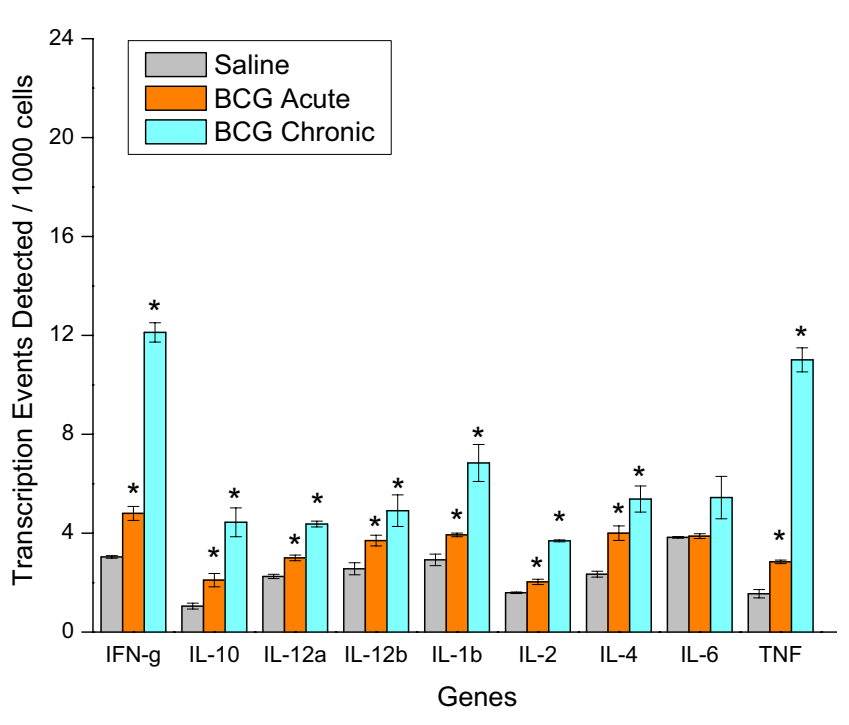

Figure I I

Chromatin immunoprecipitation (CHIP)/quantitative real-time polymerase chain reaction (Q-PCR)Based Assays. Female C57BL/6J mice were anesthetized and instilled with $200 \mu$ l of one of the following substances: BCG (TheraCys ${ }^{\circledR}$-Aventis-Pasteur; total dose of $1.35 \mathrm{mg}$ ) or pyrogen-free saline on days I, 7, 14, and 21 , as described in methods. Mice were euthanized 24 hours after a single instillation (BCG Acute) or 7 days after 4 weekly instillations (BCG Chronic). A total of 60 mice were used (20 mice per group). Bladders were removed rapidly, frozen, and shipped to Genpathway http://www.genpathway.com/ for querying the chromatin for transcription of listed genes (Genpathway's TranscriptionPath Query assay). After isolation, the chromatin was incubated with an antibody against RNA polymerase II (Abcam) to precipitate the DNA transcriptome. The final CHIP DNAs were then used as templates in Q-PCR reactions using specific primer pairs (Table Table I). Results are presented as average and standard error of Transcription Events Detected Per 1000 Cells. Results were grouped to facilitate their visualization. Cytokines. Graphics illustrated in figures $1 \mathrm{I}, 12$, and 13 present the same $X$-axis to permit comparisons between gene families.

IL-17 was significantly increased by BCG and only slightly altered by long term treatment with LPS or TNF- $\alpha$. IL-17 belongs to a family of pro-inflammatory cytokines $[40,41]$. IL-17 is a CD4 T cell-derived pro-inflammatory and pro-angiogenic cytokine that further promotes IL- 6 production and VEGF-mediated angiogenesis [42]. IL-17 is also involved in Fas ligand-induced inflammation [43]. Among the members of this family, IL-17A is the most studied, and it is secreted by activated T cells and acts on stromal cells to produce pro-inflammatory cytokines, such as GM-CSF, G-CSF, CXCL1, and CXCL8 (IL-8) [44]. IL-17 is a strong activator of neutrophil migration and infiltration, although perhaps not directly [44,45]. To our knowledge, this is the first report of an increase in urinary IL-17 release and gene expression in response to intravesical BCG.

These findings suggest that the therapeutic effects of BCG are due in part to the rapid accumulation of antigen presenting, and activated immune cells that are responsible for the production of a multiphasic immune response as demonstrated by the presence of TH1 (IFN- $\gamma$, IL-1, IL-12, and TNF- $\alpha$ ), TH2 (IL-4, IL-5, IL-6, and IL-10), and TH17 (IL-17 and IL-6) cytokines.

\section{Time-course of cytokine release}

Because of the innumerous side-effects of BCG therapy, other authors have determined the effect of different preparations [46] and regimens of intravesical BCG instillations in mice on the dynamics of Th1/Th2 cytokines $[19,47]$. It was suggested that the first BCG instillation is fundamental for the overall response [19]. In the present study, cytokine levels in the urine were elevated as early as 1 day after BCG instillation. The earliest cytokines induced by BCG included: IL-12 (p70 and p40), IL-2, IL3, IL-4, MIP- $1 \alpha$, IL-10, and KC (Figures 6, 7, 8, 9, 10). Those cytokines were released when inflammatory cell infiltrates were minimal (Figure 2A-B), and may reflect a direct effect of BCG on resident cells, such as urothelial cells and fibroblasts. Indeed, BCG stimulates IL-12 release by human urothelial cells in culture concomitantly with up regulation of toll-like receptors -2 and -4 [15]. Of interest, O'Donnel and collaborators have shown that IL-12 expression preceded the other cytokines [25]. In the present work, IFN- $\gamma$, a major Th1 cytokine, appeared in the urine late in response to BCG (Figures $6,7,8,9,10$ ). In humans, IFN- $\gamma$ was barely detectable after the first two BCG instillations, but gradually increased from the third instillation onwards [48]. The peak weekly cytokine response per patient usually occurred between the fourth and sixth treatment for IFN- $\gamma$ [49]. Others have found IFN- $\gamma$ to be a late cytokine in response to BCG, and its induction requires involvement of various endogenously produced Th1 and Th2 cytokines.

Among the cytokines released by BCG, attention has been paid to IL- 6 because its urinary levels are correlated with symptom scores in cystitis $[50,51]$ and are reduced by BCG therapy in bladder cancer [52]. However, our CHIP/ Q-PCR results did not demonstrate a significant increase in IL-6 gene following acute and chronic BCG.

Regarding the anti-inflammatory cytokines, we found that BCG also induces the release of IL-10 as early as 1 day after the first instillation. Others have found that BCG also releases IL-10 from the mouse bladder [37]. IL-10 is an important down-regulator of delayed-type hypersensitiv- 


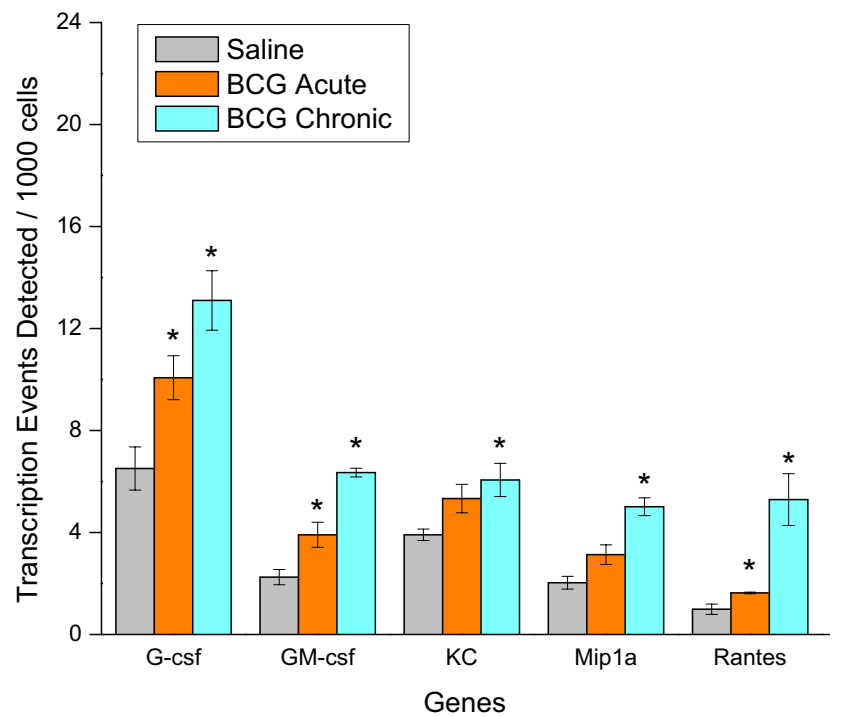

Figure 12

Chromatin immunoprecipitation (CHIP)/quantitative real-time polymerase chain reaction (Q-PCR)Based Assays. Female C57BL/6] mice were anesthetized and instilled with $200 \mu \mathrm{l}$ of one of the following substances: BCG (TheraCys ${ }^{\circledR}$-Aventis-Pasteur; total dose of $1.35 \mathrm{mg}$ ) or pyrogen-free saline on days I, 7, I4, and 2I, as described in methods. Mice were euthanized 24 hours after a single instillation (BCG Acute) or 7 days after 4 weekly instillations (BCG Chronic). A total of 60 mice were used (20 mice per group). Bladders were removed rapidly, frozen, and shipped to Genpathway http://www.genpathway.com/ for querying the chromatin for transcription of listed genes (Genpathway's TranscriptionPath Query assay). After isolation, the chromatin was incubated with an antibody against RNA polymerase II (Abcam) to precipitate the DNA transcriptome. The final CHIP DNAs were then used as templates in Q-PCR reactions using specific primer pairs (Table I).

Results are presented as average and standard error of Transcription Events Detected Per 1000 Cells. Results were grouped to facilitate their visualization. Chemokines. Graphics illustrated in figures 11,12 , and 13 present the same $X$ axis to permit comparisons between gene families.

ity (DTH). In addition, in mouse studies, the absence of IL-10 abrogated either by antibody inhibition or the use of genetically modified, IL-10 deficient mice, resulted in enhanced DTH responses [37].

Together, our results demonstrate a tractable approach for assessing the complex cytokine networks induced by BCG during both acute and chronic stages. This approach also provided the means to make relatively rigorous comparisons of the BCG response to other pro-inflammatory stimuli. Our analysis revealed that IL-1 $\beta$, IL-2, IL-3, IL-4, IL-6, IL-10,IL-17, GM-CSF, KC, and Rantes were the best discriminators of the BCG response relative to TNF- $\alpha$ and

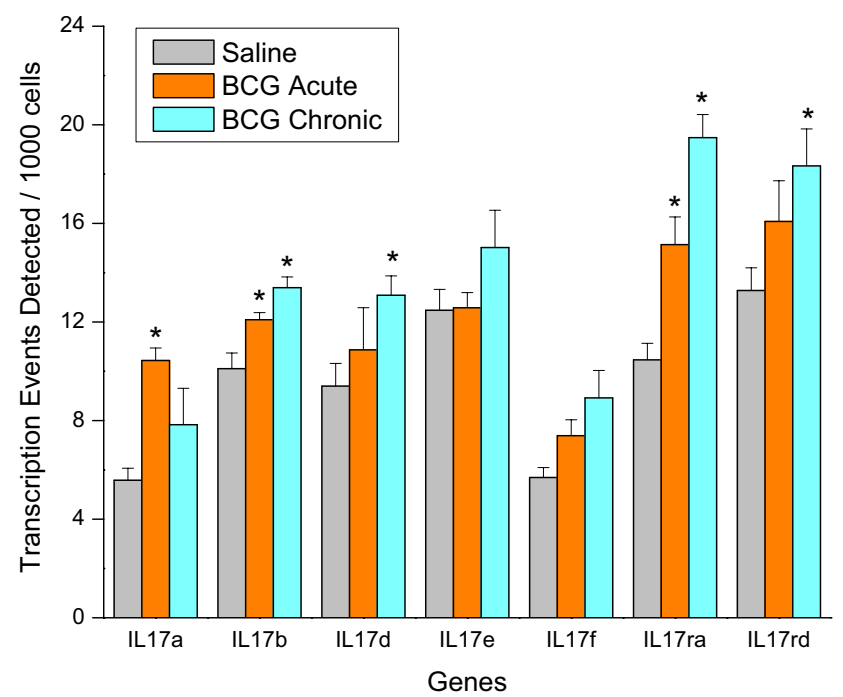

Figure 13

Chromatin immunoprecipitation (CHIP)/quantitative real-time polymerase chain reaction (Q-PCR)Based Assays. Female C57BL/6J mice were anesthetized and instilled with $200 \mu \mathrm{l}$ of one of the following substances: BCG (TheraCys ${ }^{\circledR}$-Aventis-Pasteur; total dose of $1.35 \mathrm{mg}$ ) or pyrogen-free saline on days I, 7, I4, and 21 , as described in methods. Mice were euthanized 24 hours after a single instillation (BCG Acute) or 7 days after 4 weekly instillations (BCG Chronic). A total of 60 mice were used (20 mice per group). Bladders were removed rapidly, frozen, and shipped to Genpathway http://www.genpathway.com/ for querying the chromatin for transcription of listed genes (Genpathway's TranscriptionPath Query assay). After isolation, the chromatin was incubated with an antibody against RNA polymerase II (Abcam) to precipitate the DNA transcriptome. The final CHIP DNAs were then used as templates in Q-PCR reactions using specific primer pairs (Table I). Results are presented as average and standard error of Transcription Events Detected Per 1000 Cells. Results were grouped to facilitate their visualization. IL- I 7 family. Graphics illustrated in figures $1 \mathrm{I}, 12$, and 13 present the same $X$-axis to permit comparisons between gene families.

LPS. Although the levels of IL- 2 and IL- 4 at a given time point were relatively low, our mathematical model takes into consideration the cytokines over time rather than their individual values. Using this approach, both IL-2 and IL-4 were included as discriminators for the BCG responses because of their significant $p$ values (Table 3 ).

We went further to determine whether acute and chronic BCG treatment could alter bladder gene expression. For this purpose, we examined 2 groups of mice that received BCG intravesicaly, as described in methods. The acute group was examined 24 hours after a single instillation and a chronic group was examined 7 days after 4 weekly instillations. We used a combination of CHIP assay and 
Q-PCR which has the advantage to use a quantitative method to assess genes of interest in the bladder transcriptome. This assay takes into consideration genes that are actively transcribed in contrast to cDNA array technologies that queries RNA accumulation. The results obtained in the acute group (24 hours following a single BCG instillation) indicate that with the exception of IL-6, KC, and MIP1 $\alpha$, there was a significant increase in all other RNA encoding cytokines and chemokines. In contrast, the RNA accumulation in consequence to chronic BCG instillation had a strong correlation with the levels of cytokines and chemokines and the increased urinary levels of these proteins. The disadvantage of the CHIP/Q-PCR method is the amount of chromatin necessary for CHIP, which limits this analysis to the whole bladder and not the specific layers. Our CHIP/Q-PCR results have to be taken in the context that migrating inflammatory cells, in addition to resident cells, contributed to the measured values. Future studies using individual bladder layers such as the urothelium, submucosa, and detrusor muscle should provide further detail on the source of urinary cytokines.

\section{Conclusion}

BCG induces a unique type of persisting bladder inflammation different from TNF- $\alpha$, LPS, and, most likely other classical pro-inflammatory stimuli. Among the different cytokines, this study highlighted the importance of IL- $1 \beta$, IL-2, IL-3, IL-4, IL-6, IL-10, IL-17, GM-CSF, KC, and Rantes as discriminators between overall inflammation and bladder responses to BCG instillation. To the best of our knowledge, the present work is the first to report that BCG induces an increase in the IL-17 family genes.

\section{Materials and methods Animals}

Ten to twelve week-old C57BL/6 female mice (The Jackson Laboratory; Bar Harbor, ME) were anesthetized, transurethrally catheterized as previously described $[21,24,53,54]$, and instilled with $200 \mu \mathrm{l}$ of one of the following substances: BCG (TheraCys ${ }^{\circledast}$-Aventis-Pasteur; total dose of $1.35 \mathrm{mg}$ [19]), E. coli LPS (strain 055:B5; $100 \mu \mathrm{g} /$ $\mathrm{ml}[23,24,55]), \mathrm{TNF} \alpha(1 \mu \mathrm{g} / \mathrm{ml})$, or pyrogen-free saline on days $1,7,14$, and 21 .

The urine was collected for cytokine analysis at time points indicated below ( $\mathrm{n}=6$ mice per group), and the urinary bladder was removed for morphometric analysis $(\mathrm{n}=8)$. All animal experimentation described here was performed in conformity with the "Guiding Principles for Research Involving Animals and Human Beings" (OUHSC Animal Care \& Use Committee protocols \#05088 and 05-081).

\section{Histological Analyses}

Bladders were fixed in $4 \%$ buffered formaldehyde, embedded in paraffin, cut serially into four $5-\mu \mathrm{m}$ sections ( $8 \mu \mathrm{m}$ apart), and subsequently stained with hematoxylin and eosin (H\&E) and Ziehl-Neelsen (acid fast) [36]. Macrophages were visualized using immunohistochemistry with rat anti-mouse macrophage monocyte antibody (MCA519G, Serotec LTD, Oxford, UK) and secondary antibody anti-mouse Fab-HRP, as previously described [24]. Bladder stained sections were visualized under microscope (Eclipse E600, Nikon, Lewisville, TX). All tissues were photographed at room temperature by a digital camera (DXM1200; Nikon). Exposure times were held constant when acquiring images from different groups.

\section{Morphometric analysis of inflammation}

Images were analyzed with Image-Pro Analyzer ${ }^{\circledR}$ (Media Cybernetics Inc.; Silver Spring, MD). The number of polymorphonuclear [PMNs] leukocytes was the most reproducible sign of acute bladder inflammation and, therefore, it was used for quantification. PMNs were counted in a blinded fashion in 5 random fields per slide in two non-consecutive sections per urinary bladder at $200 \times$ magnification. The number of PMNS was normalized per cross-sectional area $\left(\mu \mathrm{m}^{2}\right)$. In addition, the area of edema was determined from the same cross sections and normalized per cross-sectional area of the mucosa/ submucosa.

\section{Urine collection}

Urine for cytokine analysis was collected during early morning hours at the following time points: time 0 (previous to first instillation to determine basal release), one and seven days after a single bladder instillation, and seven days after each subsequent intravesical instillation performed at days 7,14 , and 21 . A sample of urine from each mouse was transferred to a test tube and stabilized by the addition of an equal volume of a 10-fold concentrated buffer containing $2 \mathrm{M}$ Tris-HCl (pH 7.6), 5\% BSA, 0.1\% sodium azide, and the following protease inhibitors: aprotinin, pepstatin, leupeptin at $0.01 \mathrm{mg} / \mathrm{ml}$, and AEBSF, 4 -(2-aminoethyl) benzenesulfonyl fluoride at $0.1 \mathrm{mg} / \mathrm{ml}$, as described by O'Donnell et al [25]. Samples were then stored at $-70 \mathrm{C}$ for batch cytokine analysis.

\section{Urinary Cytokines}

Buffered urine samples were thawed and fifty microliters of each sample were analyzed in duplicate on the Luminex 100 (Bio-Rad Laboratories, Hercules, CA) using a Bio-Plex Mouse Cytokine 18-Plex (catalog \#171F11181, BioRad). The Bio-Plex suspension array system, which incorporates a novel technology using color-coded microspheres, permits the simultaneous detection of 18 cytokines and chemokines in a single well of a 96-well microplate. Cytokines measured included interleukin-1 $\beta$ 
(IL-1 $\beta) ，$ IL-1 $\alpha$ ，IL-2，IL-3，IL-4，IL-5，IL-6，IL-10，IL-12 (p40), IL-12 (p70), IL-17, granulocyte colony factor (G$\mathrm{CSF})$, granulocyte macrophage colony stimulating factor (GM-CSF), interferon- $\gamma$ (IFN- $\gamma)$, tumor necrosis factor$\alpha($ TNF- $\alpha)$, keratinocyte-derived chemokine (KC), CCL3 [macrophage inflammatory protein-1 $\alpha$ (MIP-1 $\alpha)]$, and CCL5 [regulated upon activation, normal T cell expressed and secreted (RANTES)]. A broad sensitivity range of standards (Biosource International, Camarillo, CA) ranging from 1.95 to $32000 \mathrm{pg} / \mathrm{ml}$ were used to help enable the quantitation of a dynamic wide range of cytokine concentrations, and to provide the greatest sensitivity. The concentrations of analytes in these assays were quantitated using a standard curve. A 4 parameter logistic regression was performed to derive an equation that was then used to predict the concentration of the unknown samples.

\section{Chromatin immunoprecipitation (CHIP) quantitative real-} time polymerase chain reaction (Q-PCR)-Based Assays

To determine whether intravesical BCG treatment would alter bladder cytokine gene expression, we used chromatin immunoprecipitation combined with Q-PCR. For this purpose, female C57BL/6J mice were anesthetized and instilled with $200 \mu \mathrm{l}$ of one of the following substances: BCG (TheraCys ${ }^{\circledR}$-Aventis-Pasteur; total dose of $1.35 \mathrm{mg}$ ) or pyrogen-free saline on days $1,7,14$, and 21 , as described above. Mice were euthanized with pentobarbital $(200 \mathrm{mg} / \mathrm{kg}$, i.p.) 24 hours after a single instillation (BCG acute) or 7 days after 4 weekly instillations (BCG chronic). A total of 60 mice were used (20 mice per group). Bladders were removed rapidly, frozen, and were shipped to Genpathway [56] for querying the chromatin for gene transcription (Genpathway's TranscriptionPath Query assay) [57].

The urinary bladders were exposed briefly to formaldehyde for cross-linking of the proteins and DNA together, followed by sonication to fragment the DNA into pieces of approximately 300-500 base pairs. An antibody against RNA polymerase II (Abcam) was then used to precipitate the DNA transcriptome. The Ab-protein-DNA complexes were purified using beads coupled to protein A. The DNA was isolated from the complexes using a combination of heat to reverse cross-linking, RNase and proteases, and then purified using phenol extraction and EtOH precipitation. The final CHIP DNAs were then used as templates in quantitative PCR reactions using primer pairs specific for each gene of interest. Quantitative PCR was carried out using Taq polymerase (iQ SYBR Green Supermix, Bio-Rad). Primer pairs were designed using Primer 3 [58]. Details of the primer sequences are given in Table 1. The designed primers shared 100\% homology with the target sequence but no significant homology with other sequences.
Q-PCRs were run in triplicate and the values were transferred into copy numbers of DNA using a standard curve of genomic DNA with known copy numbers. The resulting transcription values for each gene were also normalized for primer pair amplification efficiency using the QPCR values obtained with Input DNA (unprecipitated genomic DNA). Results are presented as Transcription Events Detected Per 1000 Cells for each gene tested.

\section{Statistical Analysis \\ Morphometric analysis}

We did not assume equal variance because the variance of PMN population is unknown; $p$ values were calculated using a Welch's test (GraphPad Prism software version 4.0; GraphPad Software, Inc. San Diego, CA). A nominal $p$ value less than 0.05 was considered statistically significant.

\section{Q-PCR}

The difference between two mean values was analyzed with an unpaired Student's t-test (GraphPad Prism software version 4.0; GraphPad Software, Inc. San Diego, CA). A nominal $p$ value less than 0.05 was considered statistically significant.

\section{Urinary Cytokines}

The small sample sizes at each time point precluded the use of standard analysis methods such as $t$-tests comparing baseline to time $\mathrm{X}$. To gain statistical power, urinary cytokine response over time was parameterized through a "mixed model" [59] according to the following equation:

$$
\text { Cytokine Level }=\alpha * \text { Time }+\beta * \text { Trx } * \text { Time }
$$

where $\alpha$ and $\beta$ are beta coefficients, Trx is BCG vs LPS \& TNF- $\alpha$, and Time is in days. If the Trx*Time interaction was found to be significant a Trx ${ }^{*}$ Time $^{2}$ interaction was tested. Only the p value from the highest order interaction was reported. A variance component covariance matrix was used to account for the correlation structure inherent in the longitudinal measurements of cytokines. A cytokine was considered to be statistically significant if the nominal interaction $\mathrm{p}$ value was less than 0.05. All mixed model analysis was performed in the SAS system v 9.1.3 (Cary, NC).

\section{Acknowledgements}

I-This research was supported by National Institutes of Health grants 5 ROI DK066I0I-02 (RS) and 5 ROI DK055828-05 (RS).

2-The Oklahoma Medical Research Foundation (OMRF), Microarray Research Facility was supported by: 5UI9AI062629, P20 RRI5577, P20, RROI7703, P20 RR016478 from the National Institutes of Health, and HRO4-I I 0 from OCAST. 


\section{References}

I. Peters KM, Diokno AC, Steinert BW: Preliminary study on urinary cytokine levels in interstitial cystitis: does intravesical bacille Calmette-Guerin treat interstitial cystitis by altering the immune profile in the bladder? Urology 1999, 54(3):450-453.

2. Huben RP: Intravesical chemotherapy versus immunotherapy for superficial bladder cancer. Semin Urol Oncol 1996, I4(I Suppl I): I7-22

3. De Jager R, Guinan P, Lamm D, Khanna O, Brosman S, De Kernion J Williams R, Richardson C, Muenz L, Reitsma D, et al.: Long-term complete remission in bladder carcinoma in situ with intravesical TICE bacillus Calmette Guerin. Overview analysis of six phase II clinical trials. Urology |99|, 38(6):507-5I3.

4. Alexandroff $A B$, Jackson $A M, O^{\prime}$ Donnell MA, James K: BCG immunotherapy of bladder cancer: 20 years on. Lancet 1999 , 353(9 | 65): I689-1694.

5. Grossman HB: Superficial bladder cancer: decreasing the risk of recurrence. Oncology (Huntingt) 1996, I 0(I I): I6 I 7-1624. discussion 1624, 1627-1618

6. Mitropoulos DN: Novel insights into the mechanism of action of intravesical immunomodulators. In Vivo 2005 I9(3):6||-62|.

7. Decobert M, Larue H, Bergeron A, Harel F, Pfister C, Rousseau F, Lacombe L, Fradet Y: Polymorphisms of the human NRAMP I gene are associated with response to bacillus CalmetteGuerin immunotherapy for superficial bladder cancer. J Urol 2006, I75(4):|506-|5||.

8. O'Donnell M: Entrez into the immunogenetics of superficial bladder cancer response to bacillus Calmette-Guerin. J Urol 2006, I 75(4): I 197-I I98.

9. Bevers RF, Kurth $\mathrm{KH}$, Schamhart $\mathrm{DH}$ : Role of urothelial cells in BCG immunotherapy for superficial bladder cancer. $\mathrm{Br}$ / Cancer 2004, $91(4): 607-612$.

10. Abadie V, Badell E, Douillard P, Ensergueix D, Leenen PJ, Tanguy M, Fiette L, Saeland S, Gicquel B, Winter N: Neutrophils rapidly migrate via lymphatics after Mycobacterium bovis BCG intradermal vaccination and shuttle live bacilli to the draining lymph nodes. Blood 2005, I 06(5): 1843-1850.

II. Schamhart DH, Kurth KH, de Reijke TM, Vleeming R: BCG treatment and the importance of an inflammatory response. Urol Res 1992, 20(3): 199-203.

12. Zhang G, Chen F, Xu Y, Cao Y, Crist S, McKerrow A, Iwamoto Y, See WA: Autocrine over expression of fibronectin by human transitional carcinoma cells impairs bacillus CalmetteGuerin adherence and signaling. J Urol 2004, I72(4 Pt I): $1496-1500$.

13. Atkins H, Davies BR, Kirby JA, Kelly JD: Polarisation of a T-helper cell immune response by activation of dendritic cells with CpG-containing oligonucleotides: a potential therapeutic regime for bladder cancer immunotherapy. Br J Cancer 2003 89(1 2):2312-2319.

14. Akazawa T, Masuda H, Saeki Y, Matsumoto M, Takeda K, Tsujimura K, Kuzushima K, Takahashi T, Azuma I, Akira S, et al.: Adjuvantmediated tumor regression and tumor-specific cytotoxic response are impaired in MyD88-deficient mice. Cancer Res 2004, 64(2):757-764.

15. Li X, Gong ZY, Li H, Wei Q, Shi M, Yang YR: [Study on Toll-like receptors expression and cytokine production induced by bacillus Calmette-Guerin in human bladder cancer cell]. Zhonghua Wai Ke Za Zhi 2004, 42(3):I77-I8I.

16. Patard J, Guille F, Lobel B, Abbou CC, Chopin D: [Current state of knowledge concerning the mechanisms of action of BCG] Prog Urol 1998, 8(3):4I5-42I.

17. Ludwig AT, Moore JM, Luo Y, Chen X, Saltsgaver NA, O'Donnell MA Griffith TS: Tumor necrosis factor-related apoptosis-inducing ligand: a novel mechanism for Bacillus Calmette-Guerininduced antitumor activity. Cancer Res 2004, 64( I 0):3386-3390.

18. Nardini E, Morelli D, Aiello P, Besusso D, Calcaterra C, Mariani L, Palazzo M, Vecchi A, Paltrinieri S, Menard S, et al.: CpG-oligodeoxynucleotides induce mobilization of hematopoietic progenitor cells into peripheral blood in association with mouse KC (IL8) production. J Cell Physiol 2005, 204:889-895

19. De Boer EC, Rooijakkers SJ, Schamhart DH, Kurth KH: Cytokine gene expression in a mouse model: the first instillations with viable bacillus Calmette-Guerin determine the succeeding ThI response. J Urol 2003, I 70(5):2004-2008.

20. Saban MR, Nguyen NB, Hurst RE, Saban R: Gene expression profiling of inflammatory bladder disorders. Expert Rev Mol Diagn 2003, 3(2):217-235.

2I. Gonzalez RR, Fong T, Belmar N, Saban M, Felsen D, Te A: Modulating bladder neuro-inflammation: RDP58, a novel anti-inflammatory peptide, decreases inflammation and nerve growth factor production in experimental cystitis. J Urol 2005, I 73(2):630-634

22. Adams DO: The granulomatous inflammatory response. A review. Am J Pathol 1976, 84(I): |64-191.

23. Saban MR, Saban R, Hammond TG, Haak-Frendscho M, Steinberg $H$, Tengowski MW, Bjorling DE: LPS-sensory peptide communication in experimental cystitis. Am J Physiol Renal Physiol 2002, 282(2):F202-210

24. Saban MR, Nguyen NB, Hammond TG, Saban R: Gene expression profiling of mouse bladder inflammatory responses to LPS, substance P, and antigen-stimulation. Am J Pathol 2002, I 60(6):2095-2I I0.

25. O'Donnell MA, Luo $Y$, Chen $X$, Szilvasi A, Hunter SE, Clinton SK: Role of IL-I2 in the induction and potentiation of IFN. gamma in response to bacillus Calmette-Guerin. I Immunol 1999, I 63(8):4246-4252.

26. Anderson GG, Palermo Jj, Schilling JD, Roth R, Heuser J, Hultgren S]: Intracellular Bacterial Biofilm-Like Pods in Urinary Tract Infections. Science 2003, 301(5629): 105-107.

27. Peuchmaur M, Benoit G, Vieillefond A, Chevalier A, Lemaigre G, Martin ED, Jardin A: Analysis of mucosal bladder leucocyte subpopulations in patients treated with intravesical Bacillus Calmette-Guerin. Urol Res 1989, I 7(5):299-303.

28. Prescott S, James K, Hargreave TB, Chisholm GD, Smyth JF: Intravesical Evans strain BCG therapy: quantitative immunohistochemical analysis of the immune response within the bladder wall. J Urol 1992, I47(6): | 636- I642.

29. Ratliff TL, Ritchey JK, Yuan JJ, Andriole GL, Catalona WJ: T-cell subsets required for intravesical BCG immunotherapy for bladder cancer. J Urol 1993, I50(3):1018-1023.

30. Siracusano S, Vita F, Abbate R, Ciciliato S, Borelli V, Bernabei M, Zabucchi G: The Role of Granulocytes Following Intravesical BCG Prophylaxis. Eur Urol 2006, 5 I (6): I 589-I 599.

31. Suttmann H, Riemensberger J, Bentien G, Schmaltz D, Stockle M, Jocham D, Bohle A, Brandau S: Neutrophil granulocytes are required for effective bacillus calmette-guerin immunotherapy of bladder cancer and orchestrate local immune responses. Cancer Res 2006, 66( I 6):8250-8257.

32. Geisel RE, Sakamoto K, Russell DG, Rhoades ER: In vivo activity of released cell wall lipids of Mycobacterium bovis bacillus Calmette-Guerin is due principally to trehalose mycolates. J Immunol 2005, I 74(8):5007-50I5.

33. Bohle A, Gerdes J, Ulmer AJ, Hofstetter AG, Flad HD: Effects of local bacillus Calmette-Guerin therapy in patients with bladder carcinoma on immunocompetent cells of the bladder wall. J Urol 1990, I 44(I):53-58.

34. Hasan Z, Zaidi I, Jamil B, Khan MA, Kanji A, Hussain R: Elevated ex vivo monocyte chemotactic protein-I (CCL2) in pulmonary as compared with extra-pulmonary tuberculosis. BMC Immunol 2005, 6:14.

35. Olleros ML, Guler R, Vesin D, Parapanov R, Marchal G, MartinezSoria E, Corazza N, Pache JC, Mueller C, Garcia I: Contribution of transmembrane tumor necrosis factor to host defense against Mycobacterium bovis bacillus Calmette-guerin and Mycobacterium tuberculosis infections. Am J Pathol 2005, | 66(4): I 109-1 | 20.

36. Guler R, Olleros ML, Vesin D, Parapanov R, Garcia I: Differential effects of total and partial neutralization of tumor necrosis factor on cell-mediated immunity to Mycobacterium bovis BCG infection. Infect Immun 2005, 73(6):3668-3676.

37. Nadler R, Luo Y, Zhao W, Ritchey JK, Austin JC, Cohen MB, O'Donnell MA, Ratliff TL: Interleukin 10 induced augmentation of delayed-type hypersensitivity (DTH) enhances Mycobacterium bovis bacillus Calmette-Guerin (BCG) mediated antitumour activity. Clin Exp Immunol 2003, I 3 I (2):206-2 I6.

38. Saban MR, Saban R, Bjorling D, Haak-Frendscho M: Involvement of leukotrienes, TNF-alpha, and the LFA-I/ICAM-I interaction 
in substance P-induced granulocyte infiltration. I Leukoc Biol I997, 6 I (4):445-45I.

39. Walz A, Kunkel SL, RM S: C-X-C Chemokines-an overview. In Chemokines in Disease Edited by: Koch AE, Strieter RM. Austin: R. G. Landes: I-25.

40. Kawaguchi M, Adachi M, Oda N, Kokubu F, Huang SK: IL-17 cytokine family. J Allergy Clin Immunol 2004, I I4(6): I265-I 273. quiz 1274

41. Kolls JK, Linden A: Interleukin- 17 family members and inflammation. Immunity 2004, 2 I (4):467-476.

42. Takahashi H, Numasaki M, Lotze MT, Sasaki H: Interleukin- 17 enhances bFGF-, HGF- and VEGF-induced growth of vascular endothelial cells. Immunol Lett 2005, 98(2): I89-193.

43. Umemura M, Kawabe T, Shudo K, Kidoya H, Fukui M, Asano M, Iwakura Y, Matsuzaki G, Imamura R, Suda T: Involvement of IL-I 7 in Fas ligand-induced inflammation. Int Immunol 2004, 16(8): $1099-1108$.

44. Laan M, Cui ZH, Hoshino H, Lotvall J, Sjostrand M, Gruenert DC, Skoogh BE, Linden A: Neutrophil recruitment by human IL-17 via C-X-C chemokine release in the airways. J Immunol 1999 , I 62(4):2347-2352.

45. Heninger E, Hogan LH, Karman J, Macvilay S, Hill B, Woods JP, Sandor $M$ : Characterization of the Histoplasma capsulatum-induced granuloma. J Immunol 2006, I77(5):3303-33I3.

46. Hubeau C, Singer M, Lagranderie M, Marchal G, Vargaftig B: Extended freeze-dried Mycobacterium bovis Bacillus Calmette-Guerin induces the release of interleukin- 12 but not tumour necrosis factor-alpha by alveolar macrophages, both in vitro and in vivo. Clin Exp Allergy 2003, 33(3):386-393.

47. de Boer EC, Rooyakkers SJ, Schamhart DH, de Reijke TM, Kurth KH: BCG Dose Reduction by Decreasing the Instillation Frequency: Effects on Local ThI/Th2 Cytokine Responses in a Mouse Model. Eur Urol 2005.

48. Patard J], Muscatelli-Groux B, Saint F, Popov Z, Maille P, Abbou C, Chopin $D$ : Evaluation of local immune response after intravesical bacille Calmette-Guerin treatment for superficial bladder cancer. Br J Urol 1996, 78(5):709-7|4.

49. Poppas DP, Pavlovich CP, Folkman J, Voest EE, Chen X, Luster AD, O'Donnell MA: Intravesical bacille Calmette-Guerin induces the antiangiogenic chemokine interferon-inducible protein 10. Urology 1998, 52(2):268-275. discussion 275-266.

50. Lotz M, Villiger P, Hugli T, Koziol J, Zuraw BL: Interleukin-6 and interstitial cystitis. J Urol 1994, I 52(3):869-873.

5I. Erickson DR, Xie SX, Bhavanandan VP, Wheeler MA, Hurst RE, Demers LM, Kushner L, Keay SK: A comparison of multiple urine markers for interstitial cystitis. J Urol 2002, I67(6):246I-2469.

52. Erickson DR: Urine markers of interstitial cystitis. Urology 200I, 57(6 Suppl I): |5-2|.

53. Saban MR, Saban R, Hammond TG, Haak-Frendscho M, Steinberg H, Tengowski MW, Bjorling DE: LPS-sensory peptide communication in experimental cystitis. Am J Physiol-Renal 2002, 282(2):F202-F2IO.

54. Saban R, Gerard NP, Saban MR, Nguyen NB, DeBoer DJ, Wershil BK: Mast cells mediate substance $P$-induced bladder inflammation through an NK(I) receptor-independent mechanism. Am J Physiol Renal Physiol 2002, 283(4):F6I6-629.

55. Saban MR, Hellmich H, Nguyen NB, Winston J, Hammond TG, Saban R: Time course of LPS-induced gene expression in a mouse model of genitourinary inflammation. Physiol Genomics 200I, 5(3): $147-160$.

56. [http://www.genpathway.com].

57. Labhart P, Karmakar S, Salicru EM, Egan BS, Alexiadis V, O'Malley BW, Smith CL: Identification of target genes in breast cancer cells directly regulated by the SRC-3/AIB I coactivator. Proc Natl Acad Sci USA 2005, 102(5): 1339-1344.

58. [http://frodo.wi.mit.edu/cgi-bin/primer3/primer3 www.cgi].

59. Littell R, Milliken G, Stroup W, Wolfinger R, Schabenberger O: SAS for Mixed Models. Second edition. Cary, NC 2006: SAS Institute Inc; 2006.

\section{Publish with Bio Med Central and every scientist can read your work free of charge}

"BioMed Central will be the most significant development for disseminating the results of biomedical research in our lifetime. "

Sir Paul Nurse, Cancer Research UK

Your research papers will be:

- available free of charge to the entire biomedical community

- peer reviewed and published immediately upon acceptance

- cited in PubMed and archived on PubMed Central

- yours - you keep the copyright

Submit your manuscript here:

http://www.biomedcentral.com/info/publishing_adv.asp
BiolMedcentral 